\title{
Learn First, Practice Second Approach to Increase Health Professionals' Nutrition-Related Knowledge, Attitudes, and Self- Efficacy.
}

Madison E. Santella

West Virginia University, mesantella@mix.wvu.edu

Follow this and additional works at: https://researchrepository.wvu.edu/etd

Part of the Dietetics and Clinical Nutrition Commons, International and Community Nutrition

Commons, Interprofessional Education Commons, and the Other Nutrition Commons

\section{Recommended Citation}

Santella, Madison E., "Learn First, Practice Second Approach to Increase Health Professionals' NutritionRelated Knowledge, Attitudes, and Self-Efficacy." (2019). Graduate Theses, Dissertations, and Problem Reports. 3856.

https://researchrepository.wvu.edu/etd/3856

This Thesis is protected by copyright and/or related rights. It has been brought to you by the The Research Repository @WVU with permission from the rights-holder(s). You are free to use this Thesis in any way that is permitted by the copyright and related rights legislation that applies to your use. For other uses you must obtain permission from the rights-holder(s) directly, unless additional rights are indicated by a Creative Commons license in the record and/ or on the work itself. This Thesis has been accepted for inclusion in WVU Graduate Theses, Dissertations, and Problem Reports collection by an authorized administrator of The Research Repository @ WVU. For more information, please contact researchrepository@mail.wvu.edu. 
Learn first, practice second approach to increase health professionals' nutrition-related knowledge, attitudes, and self-efficacy.

\author{
Madison E. Santella
}

Thesis submitted to the Davis College of Agriculture, Natural Resources \& Design at West Virginia University

in partial fulfillment of the requirements for the degree of

Master of Science in Animal and Nutritional Sciences

Melissa Olfert, DrPH, MS, RD, LD, Chair

Tanya Horacek, PhD, RD

Ida Holáskóvá, PhD

Department of Animal and Nutritional Sciences

Morgantown, WV

2018

Keywords: Mediterranean Diet; Nutrition Education; Self-efficacy; Attitude; Health Professional; Experiential Learning; Cultural Immersion; Nutrition in Medicine; Multidisciplinary 


\begin{abstract}
Learn first, practice second approach to increase health professionals' nutrition-related knowledge, attitudes, and self-efficacy.
\end{abstract}

\title{
Madison Santella
}

The aim of this study was to assess the effectiveness of a "learn first, practice second" intervention on the nutrition-related knowledge, attitudes, and self-efficacy of multidisciplinary health professionals in West Virginia, specifically highlighting the Mediterranean Diet. Data was captured via online surveys at four time points (Baseline, Post-education, Post-immersion, Follow Up). All information was self-reported. This approach consisted of 16 weeks of online education, 2 weeks of cultural immersion in Tuscany, Italy, and a 7 month return to practice period. Data were analyzed using JMP Version Pro 12.2 and SAS Version 9.3 for Windows. Repeated measures ANOVA with irregular spacing was performed, followed by Dunnett's or Cochran-MantelHaenszel testing for variables lacking normality. The level of significance was set at 0.05 . The intervention utilized in the present study significantly improved nutrition knowledge (nonzero correlation $p=0.0136$, means score $p=0.0075)$ and self-efficacy (T0-T1 $p<0.0001$, T0-T2 $\mathrm{p}<0.0001, \mathrm{~T} 0-\mathrm{T} 3 \mathrm{p}=0.0002$ ). Further, attitudes toward nutrition in medicine were generally high at baseline for the present population. No significant differences were found in attitude between baseline and each data collection time, but the change in attitude from study beginning to end appears to be trending $(\mathrm{p}=0.0764)$. Findings from this study show that a combination of education and hands on learning experiences can be beneficial for increasing health professionals' nutrition knowledge, confidence, and potentially attitude regarding the use of culinary medicine. In order to provide more well-rounded care to patients, practitioners may benefit from participating in an intervention of this design. 
Table of Contents

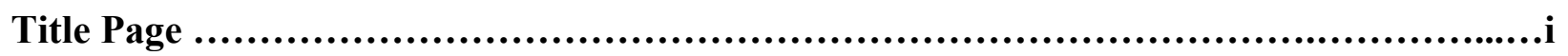

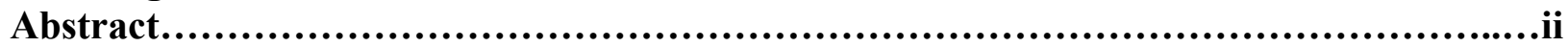

Table of Contents............................................................................iii

Acknowledgements.......................................................................iv

Chapter I: Introduction.................................................................1

Chapter II: Review of the Literature.......................................................5

Chapter III: Methodology.................................................................11

Chapter IV: Results.....................................................................15

Chapter V: Summary \& Conclusion.......................................................20

Chapter VI: Potential Publication...........................................................25

References.........................................................................................37

Appendices.....................................................................................41 


\section{Acknowledgements}

First, I would like to thank Dr. Melissa Olfert for providing me with an opportunity to join the Olfert Lifestyle Intervention Research Lab as a graduate research assistant. I would also like to express my gratitude for her willingness to conduct iCHOP Mediterranean, allowing me to combine my undergraduate degrees in both nutrition and Italian. Her time, guidance, expertise, and encouragement is unmatched.

Second, I'd like to thank my additional committee members, Dr. Tanya Horacek and Dr. Ida Holaskova for agreeing to be on my committee. Their support, feedback, and flexibility have been greatly appreciated throughout this process.

Third, I'd like to thank everyone else without whom this project would not have been possible. This includes a multitude of personnel, all of whom I wish I could list individually. From the employees in the WVU Office of Global Affairs to all of our hosts and guides in Tuscany, this journey has been made easier because of their assistance. Also, my fellow lab members, Dr. Makenzie Barr, Rebecca Hagedorn, and Rachel Wattick who have been great peers, mentors, and friends. Your efforts mean so much to me.

Lastly, thank you to those who participated in iCHOP Mediterranean. The 15 individuals who made up our sample showed tremendous compliance, enthusiasm, and understanding. It was a pleasure working with all of them. 


\section{Chapter I: \\ Introduction}

Culinary medicine is the use of nutrition related principles in the treatment and prevention of poor health conditions ${ }^{1}$. One lifestyle intervention approach that can be used in the context of culinary medicine and has shown promising health benefits is the Mediterranean Diet. This dietary pattern is usually plant based, emphasizing an intake of whole grains, fruits and vegetables, unsaturated fats, moderate dairy, limited red meat, and wine in moderation ${ }^{2}$. This pattern translates into a diet that is high in fiber, antioxidants, omega-3 and omega-6 fatty acids, and essential micronutrients. Additionally, the Mediterranean diet is low in cholesterol, saturated fats, trans fats, and added sugars. All of these properties, combined with various lifestyle components (physical activity, conviviality, de-stressing, etc), allow a Mediterranean way of life to be useful in conditions such as obesity, diabetes, cardiovascular disease (CVD), certain cancers, and mental health disorders ${ }^{3}$.

The evidence comes not only from scientific research, but also real life examples of healthfully prospering Mediterranean cultures. Currently, some locations in the Mediterranean are considered some of the healthiest in the world. In fact, the term "Blue Zones" specifically refers to regions of the world's longest-lived people. Among the original Blue Zones are Ikaria, Greece and Sardinia, Italy ${ }^{4}$. The Greek island in the Aegean Sea is home to individuals living an average of 8 years longer than Americans, who experience half the rate of heart disease and have a very low prevalence of dementia ${ }^{4}$. In the Mediterranean Sea, the Italian island of Sardinia has 10 times more centenarians than the United States ${ }^{4}$. The longevity in both areas is attributed to diet, lifestyle, and location $^{4}$.

While the Mediterranean basin is exhibiting optimal health conditions, overall world health trends are declining. According to the World Health Organization (WHO), obesity has tripled 
between 1975 and 2016, and will continue to increase ${ }^{5}$. With obesity comes other health concerns, such as cardiovascular disease, diabetes, cancer, stroke, low quality of life, mental illness, and more. The emphasis on fruits, vegetables, whole grains, and unsaturated fats in a dietary pattern consistent with the recommendations of the Mediterranean Diet Pyramid provides a myriad of beneficial components, as displayed through the previously mentioned Blue Zones.

The present study also includes an emphasis on increasing nutrition knowledge among multidisciplinary health professionals, which may ultimately influence attitudes toward nutrition in medicine and self-efficacy for incorporating nutrition into practice. Bonnaccio et al. ${ }^{6}$ surveyed individuals regarding their dietary habits and tested their nutrition knowledge. It was found that Body Mass index (BMI) and obesity were higher among those scoring low on their knowledge test. Additionally, nutrition knowledge score and Mediterranean Diet score were directly associated, that is, participants with higher test scores were more likely to follow a Mediterranean Diet pattern. This suggests that people are more likely to make a change or partake in a certain behavior, when they have sufficient information to do so. It can then be stated that education is a powerful tool in the prevention of unhealthy behaviors, and ultimately the onset of chronic disease. For this reason, it is important that professionals across all health disciplines have a foundational understanding of food and nutrition concepts, recommendations, and resources.

Unfortunately, nutrition is still struggling to establish itself as a health science, particularly within medical curricula. Therefore, practitioners who are not registered dietitians might feel they are not responsible for communicating this information, or maybe do not feel confident in their ability to do so. The National Academy of Sciences recommends at least 25 contact hours of nutrition education in a medical school curriculum ${ }^{7}$, yet only $25 \%$ of a representative sample 
of medical schools provided that much $^{8}$. This was a $5 \%$ decrease from the previous data collection 6 years prior. Even with guidelines, inclusion of nutrition in the curriculum remains inadequate. Its effects are underestimated, and as a result, the skillset of health experts are lacking. Parker et al. ${ }^{9}$ surveyed a group of health professionals and prospective students, and found that while only $6 \%$ of individuals received the desired score of $80 \%$ on the nutrition knowledge questionnaire, very few cited a lack of knowledge as a barrier in their counseling. So, not only is there a lack of nutrition knowledge among health practitioners, but also an ignorance regarding this deficit. In fact, Barratt ${ }^{10}$ suggests that there is little difference in knowledge level between the general public and health professionals. No studies specifically focusing on Mediterranean Diet knowledge among health professionals were found.

Together, the research supporting Mediterranean principles and a need for nutrition education among health professionals, prompted the present pilot study: Increasing Culinary Health Opportunities for Professionals (iCHOP) Mediterranean. This project began as a survey of nutrition knowledge, attitudes, and self-efficacy among West Virginia University medical students, and extended into a Mediterranean diet focused course geared at health professionals. With this study, researchers hope to expose working West Virginia professionals to the nutritional benefits of a Mediterranean diet and lifestyle, and provide them with opportunities to sufficiently understand all learned information through physical interaction.

It should be stated that this is not an attempt to produce doctors, dentists, therapists, etc to replace the role of dietitians. Rather, this is an effort toward empowering health professionals to provide more wholesome care, and make it evident that dietitians are a crucial part of a care team. If anything, research such as iCHOP Mediterranean may increase the amount of referrals made to dietitians, and has the potential to strengthen interdisciplinary relationships. 
This study explores a virtual method of interacting with both rural and urban health professionals across the state to supply new information that can be used towards combatting negative health trends. It is a community based participatory research approach utilizing a multidisciplinary development team, as well as a diverse group of individuals fostering dynamic conversations. By learning first and practicing second, we hope that the participants will feel empowered to use their new knowledge and share their experiences in practice. Therefore, iCHOP Mediterranean aims to improve health professionals' attitudes, knowledge, and selfefficacy regarding nutrition in medicine.

Overall, there are three aims associated with iCHOP Mediterranean. First, upon baseline measurements, we aim to evaluate the level of nutrition knowledge, attitudes, and self-efficacy among health professionals currently practicing in West Virginia. Second, we work to assess the level of these measures before and after the intervention period. Third, determine if the use of culinary medicine in practice increases after exposure to education and experiential learning related to Mediterranean principles. 


\section{Chapter II: \\ Review of the Literature}

\section{$\underline{\text { Benefits of Mediterranean Principles }}$}

Since the Mediterranean region encompasses a wide spread of cultures, there is not one Mediterranean Diet. However, the countries of this area tend to follow the same general guide. Due to the various characteristics listed in Chapter I, it is known that versions of the Mediterranean Diet can be associated with various positive health benefits. Specifically, adherence to this dietary pattern can assist in the treatment and prevention of many diseases, including obesity, diabetes, cardiovascular disease (CVD), certain cancers, and mental health disorders ${ }^{3}$.

The emphasis on fruits, vegetables, whole grains, and unsaturated fats in a dietary pattern consistent with the recommendations of the Mediterranean Diet Pyramid provides a wealth of beneficial components. In order to prevent or reverse obesity, behavioral modifications, such as diet and exercise, are needed. A Mediterranean dietary pattern can assist in this style of intervention, as it has been known to aid in weight management. One study by Zappalà et al. ${ }^{11}$, examined the role of the Mediterranean Diet in weight status among three groups of individuals: excess body weight, overweight, and obese. Results revealed that only individuals of the third weight status group showed weight changes that were inversely related to the consumption of a Mediterranean Diet, while the other two showed no relation. Rather than promoting low calories, the Mediterranean Diet focuses on metabolically healthy weight gain via inclusion of healthy fats, fruits, vegetables, and carbohydrates. This may be why the lower BMI classes remained unchanged. Ultimately, the combination of a controlled Mediterranean-like meal plan and lifestyle factors that accompany it, can help with healthy weight control. 
Cardiovascular disease is characterized as problems relating to the heart or blood vessels. The Mediterranean Diet can be beneficial for this condition, because of its fruits and vegetables, unsaturated fats, low cholesterol, and low sodium. Antioxidants and plant stanols/sterols can eliminate plaque in vessels and provide cholesterol lowering properties. The end result is lower blood pressure and improved heart function ${ }^{12}$.

High blood sugar due to problems with insulin secretion or glucose processing, also known as Diabetes, is becoming increasingly prevalent in the world. The levels of unsaturated fat and fiber recommended by a Mediterranean dietary pattern help normalize key factors in diabetic individuals, including levels of lipids, cholesterol, blood sugar, and Hemoglobin A1 $\mathrm{c}^{13}$.

The benefits of this diet are slowly being uncovered, and the more research that is conducted, the more positive health associations are being revealed. Cancer and mental illness both have compelling evidence regarding their relationship with a Mediterranean dietary pattern, but are in need of further research. Present literature states that the Mediterranean Diet promotes reduced inflammation and oxidative stress, which may lead to fewer carcinogenic compounds and therefore reduce incidence of certain cancers ${ }^{14}$. This diet also contains a wealth of $\mathrm{B}$ vitamins, that can prevent homocysteine accumulation and folate deficiency, complications that are associated with depression ${ }^{15}$.

In total, the emphasized food groups and frequency of consumption that a Mediterranean-style diet encourages, in addition to lifestyle factors (adequate rest, regular physical activity, conviviality at meal time, etc), have shown promising potential in the treatment and prevention of numerous disease states. 


\section{Nutrition Knowledge}

With rising levels of adverse health outcomes, researchers and care providers must look for effective ways to influence behavior change. One method is to increase knowledge among the general population, which has been shown to impact food intake patterns. For example, one study found that individuals with a higher level of knowledge and awareness of the food pyramid and guidelines were more likely to follow dietary recommendations ${ }^{16}$. Other research supports the fact that education is an important factor in facilitating behavior change, and suggests that sufficient nutrition knowledge is critical in practicing appropriate dietary habits ${ }^{17}$.

Studies relating knowledge to behavior, specifically in the realm of food and nutrition, have been conducted on a spectrum of populations. While the present study focuses on adults, it is important to note that the two have proven connections on younger individuals as well. One study found that a higher level of nutrition knowledge was positively associated with healthier nutritional behaviors among Sicilian children ${ }^{18}$. These results are consistent in similar populations around the world ${ }^{19,20}$. Seeing this type of relationship among the younger populations can pave the way for education and advocacy efforts in order to begin healthy habits earlier in life. Again, highlighting the importance of proper knowledge levels.

\section{Nutrition-related self-efficacy}

Like knowledge, increasing an individual's self-efficacy regarding a topic or task has been shown to impact behavior. That is, by making people feel more comfortable with nutrition, they are more likely to practice healthy eating. Adams et al. ${ }^{21}$ explains that physicians who are not comfortable with their level of nutrition competency tend to exclude or reduce their nutrition assessments and interventions. Another study showed that up and coming medical professionals 
were not confident in their nutrition assessment or counseling, and even concluded that the lack of attention to nutrition in medical school curriculums lead professionals of this field to overlook the importance of one's diet as a whole ${ }^{22}$. This is a problem, especially if patients are turning to these practitioners as the sole source of health and nutrition advice.

Based on the Social Cognitive Theory, self-efficacy is a determinant in behavior change ${ }^{23}$. This relationship has been explored in direct relation to nutrition choices, in which research found that better confidence in understanding nutrition information often leads to healthier dietary choices ${ }^{24}$. Additionally, self-efficacy can be influenced by level of knowledge ${ }^{25}$, supporting arguments of previous sections.

\section{Attitudes Toward Nutrition}

While data from research regarding other foci of this study (nutrition knowledge and selfefficacy) seem to have negative relationships among multidisciplinary health fields, practitioners generally have positive attitudes towards nutrition in medicine. A group of Canadian physicians recognized that nutrition counseling can have effects on behavior, and reported making referrals to dietitians ${ }^{26}$. Additionally, current medical students have vocalized that they value nutrition education in their schooling for overall wellness and disease prevention yet lacked adequate knowledge to effectively counsel patients on recommendations ${ }^{27}$. Even more obscure health positions that may not seem directly related to nutrition in health, such as paramedics, seem positive about the role of proper nutrition. MacDonald et al. ${ }^{28}$ found that a sample of paramedics had positive attitudes both before and after the intervention, implicating that there is some level of appreciation and acknowledgement regarding the importance of dietary habits for wellness. 


\section{Intervention Style}

The intervention style for the present study is based on a "learn first, practice second" approach. This model refers to the principles of learning first, practicing second, and lastly implementing or teaching. A meta-analysis on medical school education techniques showed that simulations in a curriculum led to improved patient care and even better patient outcomes ${ }^{29}$. Very little research focuses on this "learn first, practice second" type of intervention in order to amplify understanding, comfort, and confidence with new material and methods. The present study utilized this layout to optimize exposure and repeatedly stress concepts in different learning settings.

\section{Target Population}

As West Virginia is number one in the nation for obesity, heart attacks, and coronary heart disease $^{30}$, research targeting better health outcomes for this Appalachian region have the potential to be highly beneficial. While many studies have examined the general population of West Virginia ${ }^{31-33}$, few choose to focus their attention directly on healthcare providers. This cohort is key for disease treatment and prevention, as well as for counseling behavior change. It may prove valuable to research and intervene on practicing health professionals in an attempt to indirectly influence health of West Virginians.

\section{$\underline{\text { Summary }}$}

iCHOP Mediterranean is the culmination of numerous concepts and principles that have been supported through evidence-based research yet show room for further exploration. It is the unique fusion of culinary medicine, nutrition education, cultural diversity, and community based 
participatory work that can pave the way for novel research, but first of all, for healthier populations. 


\section{Chapter III:}

Methodology

Preparations for this study began in June of 2017. Between June and September, the itinerary was formed, the budget was made, and collaboration with the Office of International Programs was conducted to set up the web-based West Virginia University online course. Reservations to all Tuscany locations were conducted via email, initial contact was made in September 2017 and five months later vendor follow ups were completed to confirm date, time, price, and head count.

In order to obtain participants, researchers first reached out to various West Virginia chapters of health professional associations (see full list in Appendix A). A recruitment email (Appendix B) was sent to the designated contact found on their website, with the recruitment flyer attached (Appendix C). Researchers then reached out to hospitals around the state, and distributed flyers around the Morgantown area. The same recruitment email was sent to individuals within West Virginia University's Health Sciences College. Three information sessions were held in October, to allow interested individuals an opportunity to ask questions. Since these sessions took place fairly early in the recruitment process, a video covering the discussed information was designed and posted online for those who could not attend. All applications were handled by the Office of Global Affairs, and were completed online. Find the links to all online components of the recruitment process in Appendix D.

To participate in the study, an individual needed to be a currently practicing health care professional in the state of West Virginia. They also would be required to independently fund and participate in both portions of the intervention (online learning and travel to Italy). Anyone unable to meet these criteria, or who failed to complete the informed consent was excluded from 
the study. Those agreeing to participate enrolled at West Virginia University as a visiting student, and signed up for the corresponding 400/500 level course. Anyone interested in taking part in the research study then provided written informed consent at the start of the online course, marking the beginning of the intervention timeline (Appendix E). The baseline survey (Appendix F) was also distributed at this time, $\mathrm{T}_{0}$, to those who successfully gave consent. Starting on January 8, 2018 participants underwent 16 weeks of virtual education. The content was divided into 4 modules (Appendix G) which focused on the Mediterranean Diet and Lifestyle, possible implications of this way of life, and a contrast to American health-related habits. Each month individuals completed a brief survey (Appendix $\mathrm{H}$ ) reporting their level of interaction with each module (i.e. the extent to which they were utilizing the resources). The semester ended in May, at which time participants completed the post-education survey, acting as $\mathrm{T}_{1}$. It should be noted that the survey (Appendix F) was not altered for each time point. Shortly after the semester's end, the group embarked on a 2 -week cultural immersion experience through Tuscany, Italy. During this time, individuals participated in tours of production facilities for common Mediterranean staples, such as wine, olive oil, cheese, and ancient grains. The group also experienced traditional Italian meal time and engaged in multiple culinary lessons. After a 14 day specially designed itinerary (Appendix I), participants completed the post-immersion survey, $T_{2}$. No incentives were provided for participation. Additionally, participants were responsible for the $\$ 2900$ course plus travel fee, as well as their own individual airfare.

Follow-up data collection $\left(\mathrm{T}_{3}\right)$ was completed in January 2019, one year after the start of the intervention and 7 months after the end of the cultural immersion experience. Again, participants completed a survey consistent with that distributed at times $\mathrm{T}_{0}, \mathrm{~T}_{1}$, and $\mathrm{T}_{2}$. Also at this time, phone interviews were conducted to better gauge behavior change upon the 
participants' return to practice. Primary investigator Melissa Olfert facilitated each one-on-one discussion, with one note taker present to transcribe the conversation. Qualitative data from these interviews is not included in the present analysis.

The survey for iCHOP Mediterranean had influence from various outside sources, both validated and not. It was created uniquely for this study in order to properly assess all components of the intervention. The nutrition knowledge questions came from textbook information. Related subtopics of culinary, cultural, and eating competence were altered from Papadopoulos et al. ${ }^{34}$ and Lohse et al. ${ }^{35}$. Questions regarding participant attitudes toward nutrition in medicine, as well as readiness to change, were adapted from the Nutrition in Patient Care Survey (NIPS) ${ }^{36}$. Lastly, sections relating to self-efficacy and practice behavior were constructed with reference to Mihalynuk et al. ${ }^{37}$. The Mediterranean Diet Score assessment consisted of 21 questions compiled from multiple validated tools ${ }^{38,39}$. All surveys were conducted electronically via Qualtrics. This study was conducted in accordance with the Declaration of Helsinki, and the protocol was approved by the Institutional Review Board at West Virginia University (1709753932).

Data were analyzed using JMP and SAS software (JMP®, Version Pro 12.2, SAS Institute Inc., Cary, NC, USA, Copyright ${ }^{C 2015}$; SAS ${ }^{\circledR}$, Version 9.3, SAS Institute Inc., Cary, NC, USA, Copyright (C2002-2010). Survey responses were reported as ratings on ordinal item scales. Results are reported as means along side standard deviations. Response variables collected at each time point were analyzed via irregularly-spaced repeated measures analysis of variance (ANOVA), where the repeated factor was time of survey collection. For analysis, $\mathrm{T}_{0}, \mathrm{~T}_{1}, \mathrm{~T}_{2}$, and $\mathrm{T}_{3}$ time points were marked as actual days from the beginning of the study, $0,119,154$, and 375 , respectively. Data screening revealed a lack of normality and left-skewness for the variables 
knowledge and self-efficacy. The latter was corrected using a cube transformation, while $3 / 4$ of the knowledge time points remained left skewed. Mediterranean Diet Score, attitude, and cube transformed self-efficacy were compared to the baseline measure through Dunnett's multiple comparison testing. Knowledge data were analyzed via Cochran-Mantel-Haenszel testing, while controlling for subject, to assess correlation for this ordinally scaled item.

In all statistical analyses, significance criterion alpha for all tests was 0.05 and a statistical trend was declared when $\mathrm{p}<0.1$. 


\section{Chapter IV: \\ Results}

While complete data measures included nutrition knowledge, self efficacy, attitudes, readiness to change, culinary/cultural/eating competence, and practice behavior, only the first three were analyzed at this time. These factors were measured at four time points to determine effectiveness of education and immersion independently and combined.

\section{$\underline{\text { Demographics }}$}

A total of 18 individuals enrolled in the study, of which 3 were excluded for not meeting inclusion criteria (i.e. practicing in a health professional field, willingness to participate in both the online education and travel abroad components, West Virginia resident, completion of informed consent). The final sample ( $\mathrm{N}=15)$ was $73 \%$ female ranging from ages 22 to 65 (mean age: $43 \pm 16.92)$. Table 1 enlists the sample breakdown by discipline.

Table 1. Breakdown of Sample by Discipline

\begin{tabular}{|l|l|l|}
\hline Discipline & Frequency (N) & Percent (\%) \\
\hline Nutrition & 5 & $33 \%$ \\
\hline Dental (total) & 3 & $20 \%$ \\
Dentist & 2 & $13 \%$ \\
Dental Hygienist & 1 & $7 \%$ \\
\hline Respiratory Therapy & 1 & $7 \%$ \\
\hline Psychology & 1 & $7 \%$ \\
\hline Nursing & 1 & $7 \%$ \\
\hline Health Department IT & 1 & $7 \%$ \\
\hline Life Coach & 1 & $7 \%$ \\
\hline Physician (total) & 2 & $13 \%$ \\
Family & 1 & $7 \%$ \\
OBGYN & 1 & $7 \%$ \\
\hline
\end{tabular}


At baseline, the group had an average Body Mass Index (BMI) of $29.15 \pm 7.96$, followed by $26.85 \pm 5.21$ at the post-education time, $28.19 \pm 6.24$ at post-immersion, and $28 \pm 5.88$ at the follow up time.

While BMI fluctuated, mean Mediterranean Diet Score improved steadily from $12.6 \pm$ 3.09 at baseline to $14.27 \pm 2.74$ at $\mathrm{T}_{1}$ and again to $15 \pm 2.33$ at $\mathrm{T}_{2}$. Mediterranean Diet Score then fell slightly during the 7 month return to practice, with participants reporting an average score of $14.5 \pm 2.93$. While differences in mean Mediterranean Diet Score between baseline and posteducation, as well as baseline and follow up were not significantly different $(p=0.1191, p=0.1849$ respectively), mean Mediterranean Diet Score from baseline to post-immersion significantly improved $(\mathrm{p}=0.0259)$.

\section{$\underline{\text { Knowledge }}$}

There were a total of 8 questions regarding information on the Mediterranean Diet. Responses were coded (correct $=1$, incorrect $=0$ ) and summed for an overall knowledge score. Possible score ranged from 0 , no correct answers, to 8 , all correct answers. Overall average group knowledge scores with standard deviations are listed in Table 2 below.

Table 2. Nutrition Knowledge Across the Intervention Period

\begin{tabular}{|c|c|c|c|c|}
\hline & $\begin{array}{c}\text { Baseline } \\
\left(\mathrm{T}_{0}\right)\end{array}$ & $\begin{array}{c}\text { Post- } \\
\text { Education } \\
\left(\mathrm{T}_{1}\right)\end{array}$ & $\begin{array}{c}\text { Post- } \\
\text { Immersion } \\
\left(\mathrm{T}_{2}\right)\end{array}$ & $\begin{array}{c}\text { Follow Up } \\
\left(\mathrm{T}_{3}\right)\end{array}$ \\
\hline & Mean $\pm \mathrm{SD}$ & Mean $\pm \mathrm{SD}$ & Mean $\pm \mathrm{SD}$ & Mean $\pm \mathrm{SD}$ \\
\hline $\begin{array}{l}\text { Average Nutrition } \\
\text { Knowledge Score }\end{array}$ & $6.20 \pm 1.26$ & $7.27 \pm 1.10$ & $7.13 \pm 0.83$ & $7.29 \pm 1.07$ \\
\hline
\end{tabular}

Results from Nutrition Knowledge Questionnaire

Highest possible total score of 8 . 
The integers (1-8) were used to score the knowledge level for both Cochran-MantelHaenszel statistics to assess mean scores and for the correlation statistics ${ }^{40}$. When controlling for subject, the nonzero correlation statistic $(\mathrm{p}=0.0136)$ demonstrated a highly significant monotone association between progression of days and knowledge level scores. The means score statistics (Cochran-Mantel-Haenszel) was also significant $(\mathrm{p}=0.0075)$, indicating the scores changed in relation with time (intervention) progress.

\section{$\underline{\text { Attitudes }}$}

Each participant rated their feelings toward ten total statements relating to nutrition in medicine on a scale of $0-10$, with lower values signifying disagreement and higher values signifying agreement. These ratings were then summed (inverted as necessary) and used to generate a total attitude score. Table 3 shows average group attitude at each data collection time point across the length of the study, and demonstrates that lowest attitudes occurred at $\mathrm{T}_{0}$ while highest attitudes were seen at $\mathrm{T}_{3}$.

Table 3. Attitudes Across the Intervention Period

\begin{tabular}{|c|c|c|c|c|}
\hline & Baseline $\left(\mathrm{T}_{0}\right)$ & $\begin{array}{c}\text { Post- } \\
\text { Education } \\
\left(\mathrm{T}_{1}\right)\end{array}$ & $\begin{array}{c}\text { Post- } \\
\text { Immersion } \\
\left(\mathrm{T}_{2}\right)\end{array}$ & $\begin{array}{c}\text { Follow Up } \\
\left(\mathrm{T}_{3}\right)\end{array}$ \\
\hline & Mean $\pm \mathrm{SD}$ & Mean $\pm \mathrm{SD}$ & Mean $\pm \mathrm{SD}$ & Mean $\pm \mathrm{SD}$ \\
\hline $\begin{array}{c}\text { Average Sample } \\
\text { Attitude }\end{array}$ & $83.67 \pm 11.97$ & $86.8 \pm 7.97$ & $87.93 \pm 10.26$ & $91.57 \pm 5.96$ \\
\hline
\end{tabular}

Results from Attitude Survey Highest possible total score of 100 .

Attitude data were analyzed using repeated measures ANOVA with irregular spacing, followed by Dunnett's multiple comparisons. 
Table 4. Results of Dunnett's Multiple Comparisons Testing on Group Attitude

\begin{tabular}{|c|c|c|c|c|}
\hline Comparison & Estimate & $\begin{array}{c}\text { Standard } \\
\text { Error }\end{array}$ & $\begin{array}{c}\text { Degrees of } \\
\text { Freedom }\end{array}$ & Adjusted P \\
\hline $\mathrm{T}_{0}-\mathrm{T}_{1}$ & 3.1333 & 2.9340 & 41 & 0.5471 \\
\hline $\mathrm{T}_{0}-\mathrm{T}_{2}$ & 4.2667 & 3.1186 & 41 & 0.3631 \\
\hline $\mathrm{T}_{0}-\mathrm{T}_{3}$ & 7.8418 & 3.5425 & 41 & $0.0764^{\dagger}$ \\
\hline
\end{tabular}

Concise differences of least square means data results

$\mathrm{T}_{0}$ refers to baseline, $\mathrm{T}_{1}$ refers to the post-education time point, $\mathrm{T}_{2}$ refers to the post-immersion time point, $\mathrm{T}_{3}$ refers to the follow up time point

$\dagger_{\mathrm{p}<0.1 \text {, trending }}$

Results (Table 4) revealed no significant differences in group attitude from baseline to post-education, post-immersion, or follow up. However, there appears to be a statistical trend $(p=0.0764)$ between baseline and follow up.

\section{$\underline{\text { Self-Efficacy }}$}

Subjects responded to 14 survey questions relating to self-efficacy in terms of their comfort level with different topics and behaviors. Responses were provided on a scale of not applicable, not proficient, somewhat proficient, very proficient. For analysis, these responses were coded as 1, 2, 3, and 4 accordingly. Individual overall self-efficacy ranged from 0 to 56 . Following the same method as performed for each of the above data measures, average selfefficacy score was calculated for the group at each time point (Table 4). 
Table 4. Self-Efficacy Across the Intervention Period

\begin{tabular}{|c|c|c|c|c|}
\hline & Baseline $\left(\mathrm{T}_{0}\right)$ & $\begin{array}{c}\text { Post- } \\
\text { Education }\left(\mathrm{T}_{1}\right)\end{array}$ & $\begin{array}{c}\text { Post- } \\
\text { Immersion }\left(\mathrm{T}_{2}\right)\end{array}$ & $\begin{array}{c}\text { Follow Up } \\
\left(\mathrm{T}_{3}\right)\end{array}$ \\
\hline & Mean $\pm \mathrm{SD}$ & Mean $\pm \mathrm{SD}$ & Mean $\pm \mathrm{SD}$ & Mean $\pm \mathrm{SD}$ \\
\hline $\begin{array}{c}\text { Average Sample } \\
\text { Self-efficacy }\end{array}$ & $34.6 \pm 13.80$ & $44.80 \pm 11.33$ & $47.13 \pm 9.55$ & $48.5 \pm 8.05$ \\
\hline
\end{tabular}

Results from Self-Efficacy survey

Highest possible total score of 56.

Self-efficacy data were analyzed using repeated measures ANOVA with irregular spacing. Data at baseline was normally distributed, while data for times $T_{1}, T_{2}$, and $T_{3}$ were leftskewed. A cube transformation was performed to correct these abnormal distributions. The repeated measures ANOVA was followed by Dunnett's multiple comparisons.

Table 5. Results of Dunnett's Multiple Comparisons Testing on Group Self-Efficacy

\begin{tabular}{|l|l|l|l|l|}
\hline Comparison & $\begin{array}{l}\text { Estimate } \\
\text { (cubed value) }\end{array}$ & $\begin{array}{l}\text { Standard Error } \\
\text { (cubed value) }\end{array}$ & $\begin{array}{l}\text { Degrees of } \\
\text { Freedom }\end{array}$ & Adjusted P \\
\hline $\mathrm{T}_{0}-\mathrm{T}_{1}$ & 45353 & 8440.24 & 41 & $<0.0001^{*}$ \\
\hline $\mathrm{T}_{0}-\mathrm{T}_{2}$ & 56646 & 9458.34 & 41 & $<0.0001^{*}$ \\
\hline $\mathrm{T}_{0}-\mathrm{T}_{3}$ & 60974 & 13740 & 41 & $0.0002^{*}$ \\
\hline
\end{tabular}

Concise differences of least square means data results

$\mathrm{T}_{0}$ refers to baseline, $\mathrm{T}_{1}$ refers to the post-education time point, $\mathrm{T}_{2}$ refers to the post-immersion time point, $\mathrm{T}_{3}$ refers to the follow up time point

${ }^{*} \mathrm{p}<0.05$, statistical significance

Results (Table 5) show that average self-efficacy scores at post-education, postimmersion, and follow up were significantly different from average self-efficacy at baseline. Specifically, the values were higher at each $\mathrm{T}_{1}, \mathrm{~T}_{2}$, and $\mathrm{T}_{3}$ compared to baseline. 


\section{Chapter V: Summary \& Conclusions}

This study aimed to identify if a "learn first, practice second" approach could be effective in increasing the nutrition related knowledge, attitudes, and self-efficacy of currently practicing health professionals in West Virginia.

It was found that nutrition knowledge increased across the intervention period. More specifically, there was a 1.17-point rise in knowledge score from baseline to post-education, a slight decrease in knowledge score (0.14-point deficit) after the immersion experience, and a 0.16-point increase upon follow up. Overall, average sample knowledge score increased by 1.09 on an 8-point scale from baseline to follow up. Analysis revealed that there was significant $(p=0.0325)$ shift in row mean scores, signifying that knowledge score is directly associated with time across the intervention.

While it is not surely known why knowledge scores fluctuated as they did, researchers speculate it could be due to the lack of nutrition information provided concretely to participants after the completion of the online course. Participants had the curriculum still at their disposal, however, reviewing the information was voluntary. Additionally, during the travel period, any education that occurred was delivered verbally, so retention may have been low. Overall, nutrition knowledge from baseline to post-immersion experienced a statistically significant increase, implying that the iCHOP Mediterranean intervention was successful in providing nutrition education. Other research supports the present findings that providing education and/or hands on learning can improve nutrition knowledge. Researchers from the University of Minnesota - Twin Cities found that a short-term education program and the inclusion of experiential skill building positively affected their population's food knowledge level ${ }^{41}$. Another 
study suggests that e-learning interventions can be helpful in improving nutrition knowledge among non-nutrition professionals ${ }^{42}$.

In terms of sample attitudes toward nutrition in medicine, participants were increasingly positive as the study progressed. Attitude increased 7.9-points on a scale of 0 to 100 from baseline to follow up. Reported attitudes at post-education, post-immersion, and follow up were not found to be significantly different from that at baseline. However, the difference in attitudes at baseline and follow up appear to be trending.

Perhaps this is due to the fact that the study subjects entered the intervention with already positive attitudes, which were not highly altered by the content but rather reinforced or solidified. This is consistent with other research that has shown how multidisciplinary health professionals recognize the importance of nutrition in health. In fact, a group of Canadian physicians vocalized that nutrition counseling can have effects on behavior, and reported that they often make referrals to dietitians ${ }^{26}$. Additionally, current medical students have stated that they value nutrition education in their schooling for overall wellness and disease prevention yet lacked adequate knowledge to effectively counsel patients on recommendations ${ }^{27}$. Even more obscure health positions that may not seem directly related to nutrition in health, such as paramedics, seem positive about the role of proper nutrition. MacDonald et al. ${ }^{28}$ found that a sample of paramedics had positive attitudes both before and after the intervention, implicating that there is some level of appreciation and acknowledgement regarding the importance of dietary habits for wellness.

Lastly, self-efficacy increased a total of 13.9 points on a 56-point scale from first to last data collection. Average self-efficacy at baseline was found to be significantly different from levels at all other time points. The change in participant reported self-efficacy after the 16 -week 
online education portion was far greater $(+10.2)$ than that after the immersion $(+2.33)$ and the 7 month return to practice $(+1.37)$. Researchers attribute this to the concurrent increase in nutrition knowledge. As previously mentioned in Chapter II, exposing individuals to some form of education can result in a higher level of comfort with topics to facilitate behavior change ${ }^{17}$. The less dramatic rises in self-efficacy at the latter two time points may be due to the fact that confidence increased so greatly upon the education period, that the hands-on practice reinforced rather than improved and this new level of confidence was strengthened when implementing new concepts and behaviors in participants' every day lives. Overall, this style intervention appears beneficial in increasing self-efficacy of West Virginia health professionals. That is, after undergoing nutrition education in addition to partaking in first hand experiences, confidence to incorporate Mediterranean principles into regular practice is higher. Results of the present study are concurrent with other research that has shown how an online nutrition education intervention can be successful for improving self-efficacy for diet-related behavior change ${ }^{43}$. Additionally, Franko et al. found that self-efficacy is an important variable in health behavior change, and that a nutrition education website appeared beneficial for increasing the self-efficacy of $\operatorname{participants}^{44}$.

This study does have limitations. First, the sample size of 15 participants may be thought to hinder precision or devalue the results. This head count was chosen due to space restrictions for activities and accommodations abroad. While there are some drawbacks to a study with such a small sample, it allowed iCHOP Mediterranean to be completed in a timely manner and also acted as a feasibility study to test the potential outcomes of a certain intervention style. Based on the results, a similar study can be conducted on a larger sample or varying populations in order to capture more extensive data. Second, the survey used to collect data at each time is not yet 
validated. The survey was constructed from a mix of other validated and not validated tools, but was built based on previous literature with the aims of the present study in mind. Researchers may work toward validation. Third, all data was self-reported. While researchers feel that the relationship with participants fostered honesty, it must be considered that there is room for false or misreported information.

Results from iCHOP Mediterranean show that a learn first, practice second style intervention can positively impact nutrition-related knowledge and self-efficacy, and could potentially improve attitudes toward nutrition in medicine. Findings from the present study are consistent with the literature, as evidenced by the contents of Chapter II. On the basis of principles explained by the Social Cognitive Theory, it is thought that by implementing an intervention like that of iCHOP Mediterranean in order to improve knowledge, attitude, and selfefficacy, researchers have the potential to facilitate behavior change. Further, by educating health professionals on incorporating healthy principles into their regular practice behavior and allowing them physical exposure to exemplar cultures, the health of the general population may be improved.

Future research should explore a similar intervention on a larger scale, wider array of health disciplines, or more specific cohorts within individual fields. Since the results regarding attitude toward nutrition in medicine were only trending toward statistical significance in the present study, further examination into what may influence an individual's attitude is needed. Additionally, it may prove beneficial to explore more exact components of nutrition education and experiential learning that influence knowledge, attitudes, and self-efficacy.

Overall, the results from four time points during the intervention period of iCHOP Mediterranean, a learn first, practice second style approach, reveal that this feasibility study 
warrants implementation in order to diversify multidisciplinary care and positively impact patient or client health. 


\title{
Chapter VI: \\ Potential Publication
}

\section{The effect of a "learn first, practice second" style approach on West Virginia health professionals' nutrition-related knowledge, attitudes, and self-efficacy}

\begin{abstract}
Objective: To assess the effectiveness of a "learn first, practice second" intervention on the nutrition-related knowledge, attitudes, and self-efficacy of multidisciplinary health professionals in West Virginia, specifically highlighting the Mediterranean Diet. Design: This approach consisted of 16 weeks of online education, 2 weeks of cultural immersion in Tuscany, Italy, and a 7 month "return to practice" period. Data was captured via online surveys at four time points (Baseline, Post-education, Post-immersion, Follow Up). All information was self-reported. Main Outcome Measures: Survey questions focused on nutrition-related knowledge, attitudes, and self efficacy, as well as demographic criteria and Mediterranean Diet Score. Each measure was collected using unique ordinal item scales. Analysis: Repeated measures ANOVA with irregular spacing was used, followed by Dunnett's or Cochran-Mantel-Haenszel testing. Results: Individuals were 15 health practitioners currently practicing in the state of West Virginia who agreed to both the online education and travel abroad experience. The present study significantly improved participant nutrition knowledge (nonzero correlation $\mathrm{p}=0.0136$, means score $\mathrm{p}=0.0075$ ) and self-efficacy $\left(\mathrm{T}_{0}-\mathrm{T}_{1} \mathrm{p}<0.0001, \mathrm{~T}_{0}-\mathrm{T}_{2} \mathrm{p}<0.0001, \mathrm{~T}_{0}-\mathrm{T}_{3} \mathrm{p}=0.0002\right)$. Further, attitudes toward nutrition in medicine were generally high at baseline for the present population. No significant differences were found in attitude between baseline and each data collection time, but the change in attitude from study beginning to end appeared to be trending $(p=0.0764)$. Conclusions and Implications: Findings from this study suggest that a combination of education and hands on learning experiences can be beneficial for increasing health professionals' nutrition knowledge, confidence, and potentially attitude regarding the use of culinary medicine. In order to provide more well-rounded care to patients, practitioners may benefit from participating in an intervention of this design.
\end{abstract}

Keywords: Mediterranean Diet; Nutrition Education; Self-efficacy; Attitude; Health Professional; Experiential Learning; Cultural Immersion; Nutrition in Medicine; Multidisciplinary 


\section{INTRODUCTION}

There are many factors involved in influencing healthy dietary patterns and increasing nutrition knowledge and self-efficacy of health professionals. One area of study that can positively influence the use of nutrition principles by health professionals is culinary medicine ${ }^{1}$. Culinary medicine is the use of nutrition in the treatment and prevention of poor health conditions. It has previously been explained as the fusion of cooking as an art form, nutrition in relation to health, and the science of medicine ${ }^{1}$. One lifestyle approach that can be used in the context of culinary medicine and has shown positive health benefits is the Mediterranean Diet ${ }^{2}$. This dietary pattern is predominately plant-based, emphasizing an intake of whole grains, fruits and vegetables, unsaturated fats, moderate dairy, limited red meat, and wine in moderation ${ }^{3}$. This pattern translates into a diet that is high in fiber, antioxidants, omega- 3 and omega- 6 fatty acids, and essential micronutrients. Additionally, the Mediterranean diet is low in cholesterol, saturated fats, trans fats, and added sugars. All of these properties, combined with various lifestyle components (e.g. physical activity, conviviality, de-stressing), allow a Mediterranean way of life to be useful in conditions such as obesity, diabetes, cardiovascular disease (CVD), certain cancers, and mental health disorders ${ }^{2}$.

To influence healthy dietary patterns, a foundational knowledge of nutrition is an important component and is essential for the practice of culinary medicine. Specifically, nutrition knowledge has been shown to influence eating pattern and affect indicators of poor health, such as obesity and diabetes ${ }^{4-6}$. This suggests that people are more likely to partake in a certain behavior, when they have sufficient information to do so. Thus, it can be stated that education may be a powerful tool in the prevention of unhealthy dietary patterns, and ultimately the onset of chronic disease. Therefore, it is recommended that professionals across all health disciplines have a foundational understanding of food and nutrition concepts, recommendations, and resources.

Unfortunately, nutrition struggles to maintain recognition as a health science, particularly within medical curricula ${ }^{7}$. Therefore, practitioners who are not registered dietitians might feel they are not responsible for, or lack the confidence for, incorporating nutritional recommendations into patient interactions. The National Academy of Sciences recommends at least 25 contact hours of nutrition education in a medical school curriculum ${ }^{8}$, yet findings from research conducted in 2010 revealed that only $25 \%$ of a representative sample of medical schools met this critertia ${ }^{7}$. More alarmingly, this was a 5\% decrease from the previous data collection 6 years prior. Even with guidelines, inclusion of nutrition in the curriculum remains inadequate. The effects that nutrition can have on health status are underestimated, and as a result, the skillset of health experts are lacking. Parker et al. ${ }^{9}$ surveyed a group of health professionals and prospective students, and found that while only $6 \%$ of individuals received the desired score of $80 \%$ on the nutrition knowledge questionnaire, very few cited a lack of knowledge as a barrier when counseling patients. This highlights not only the lack of nutrition knowledge among health practitioners, but also an ignorance regarding knowledge deficit. In fact, Barratt ${ }^{10}$ suggests that there is little difference in knowledge level between the general public and health professionals. When looking at Mediterranean knowledge among health professionals, to our knowledge, no studies have been conducted.

Like knowledge, increasing an individual's self-efficacy regarding a topic or task has been shown to impact behavior. According to the Social Cognitive Theory (SCT) ${ }^{11}$, an important determinant of behavior is self-efficacy, or one's judgements of their abilities to perform a given 
action $^{12 .}$ That is, by making people feel more comfortable with nutrition-related information, they are more likely to practice healthy eating. Self-efficacy has been positively linked to actual behavior in terms of fruit and vegetable consumption, avoiding fatty foods, and participating in physical activity, and also plays an important role in the treatment of chronic disease ${ }^{12,13}$.

Additionally, an individual's attitude towards a topic is likely to influence their adherence to a behavior or action ${ }^{14}$. Fortunately, practitioners generally have positive attitudes towards nutrition in medicine. A group of Canadian physicians recognized that nutrition counseling can have effects on behavior, and reported making referrals to dietitians ${ }^{15}$. Additionally, current medical students have vocalized that they value nutrition education in their schooling for overall wellness and disease prevention yet lacked adequate knowledge to effectively counsel patients on recommendations ${ }^{16}$. With that being said, limited studies focus on the source of these attitudes or the factors that may influence professionals' beliefs.

In order to investigate the best way to address and impact nutrition knowledge, selfefficacy, and attitudes, the intervention style for the present study is based on a "learn first, practice second" approach. This model refers to the principles of learning first, practicing second, and ultimately implementing or teaching ${ }^{17}$. Very little research focuses on this learn first, practice second type of intervention in order to amplify understanding, comfort, and confidence with new material and methods. However, immersion learning has shown success for furthering comprehension $^{18,19}$. The present study combined traditional education with experiential learning to optimize exposure and repeatedly stress concepts in different learning settings.

The present pilot feasibility study, known as Increasing Culinary Health Opportunities for Professionals (iCHOP) Mediterranean, aimed to examine the effectiveness of a "learn first, practice second" intervention on the knowledge, attitudes, and self-efficacy of multidisciplinary health professionals in West Virginia regarding nutrition in medicine, with a focus on the Mediterranean Diet. This study explores a virtual method of interacting with both rural and urban health professionals to supply new information that can be used towards combatting negative health trends.

\section{METHODS}

Preparations for this study began in June of 2017. Between June and September, the itinerary was formed, the budget was established, and collaboration with West Virginia University's Office of Global Affairs was conducted to set up the program. The web-based course was created via the West Virginia University eCampus portal, with participants receiving visiting student access for the 16-weeks of virtual education. The cultural immersion portion of the intervention took shape as a 2-week study abroad experience in Tuscany, Italy. This study was conducted in accordance with the Declaration of Helsinki, and the protocol was approved by the Institutional Review Board at West Virginia University (1709753932).

\section{Recruitment}

In order to obtain participants, researchers connected with various West Virginia chapters of health professional associations. A recruitment email was sent to the designated contact found on association websites, with the recruitment flyer attached. Researchers also contacted hospitals around the state, and distributed flyers throughout the local area surrounding the university. The same recruitment email was sent to individuals within West Virginia University's health sciences 
college. Three information sessions were held in October, to allow interested individuals an opportunity to ask questions. Since these sessions took place fairly early in the recruitment process, a video covering the discussed information was designed and posted online for those who could not attend. All applications were handled by the Office of Global Affairs and were completed online.

\section{Subjects}

The present research consisted of a convenience sample of 15 health professionals currently practicing in the state of West Virginia. To participate in the study, an individual needed to be a currently practicing health care professional in the state of West Virginia. They also were required to independently fund and participate in both portions of the intervention (online learning and travel to Italy). Anyone unable to meet these criteria, or who failed to complete the informed consent, were excluded from the study.

Those agreeing to participate enrolled at West Virginia University as a visiting student and signed up for the corresponding 400/500 level course. Anyone interested in taking part in the research study provided written informed consent at the start of the online course, marking the start of the intervention timeline. No incentives were provided for participation.

\section{Measures}

The 51-item survey for iCHOP Mediterranean was created uniquely for this study, but had influence from evidence based sources. A version of this tool was originally pilot tested on a sample of West Virginia University medical students $(n=56)^{20}$. Based on the feedback and results from that small sample, two researchers independently refined the survey and agreed upon a final version to best accompany the intervention period. A third researcher was utilized as a tiebreaker when necessary to dispute any disagreements. No changes were made to the survey tool across the study timeline. That is, details described below are true for data collection at all four time points.

\section{Demographics}

Demographic data was self-reported to identify age, sex, height in inches, and weight in kilograms. Body Mass Index (BMI) was calculated using the standard formula of weight in kilograms divided by squared height in meters.

\section{Mediterranean Diet Score}

The Mediterranean Diet Score assessment was compiled from multiple validated tools ${ }^{21,22}$ in order to adequately assess both dietary and lifestyle changes. Mediterranean Diet Score accounted for 21 of the total 51 survey questions. Participants provided a yes or no response to these items, signifying whether or not they regularly performed Mediterranean-like behaviors. For example, consuming fish 2-3 times per week, using olive oil as the main fat in cooking, and getting 6-7 hours of sleep per night.

\section{Nutrition Knowledge}

The 8 nutrition knowledge questions focused on the basics of a Mediterranean dietary pattern, as described by cultural experts ${ }^{23}$, on the basis of principles previously explained. For 
example, participants were asked "If adhering to a Mediterranean diet pattern, which item should be consumed least?" and "Which type of fat is prominent in the Mediterranean Diet, associating it with good heart health?", among others. Responses were coded (correct $=1$, incorrect $=0$ ) and summed for an overall knowledge score. Possible score ranged from 0, no correct answers, to 8 , all correct answers.

\section{Attitudes}

Questions regarding participant attitudes toward nutrition in medicine, as well as readiness to change, were adapted from the Nutrition in Patient Care Survey (NIPS) ${ }^{24}$, in order to develop a set of 10 questions that appropriately reflected the Mediterranean foci of the online learning modules and hands on experiences. Each participant rated their feelings toward ten total statements relating to nutrition in medicine on a scale of $0-10$, with lower values signifying disagreement and higher values signifying agreement. Examples of statements gauging participant attitudes toward nutrition in medicine include, "Nutritional assessment should be included in any routine appointment", "I have an obligation to improve the health of my patients including discussing nutrition with them", and "It is not worth my time to counsel patients with poor dietary patterns about nutrition".

\section{Self-Efficacy}

Questions relating to self-efficacy and practice behavior were constructed with reference to Mihalynuk et al. ${ }^{25}$. The final survey used in the present study included 14 concepts or actions (i.e. MyPlate guide, benefits of a Mediterranean Diet, providing nutrition education for a patient with diabetes, etc) for which participants rated their perceived level of proficiency on a scale of not applicable, not proficient, somewhat proficient, very proficient. For analysis, these responses were coded as 1, 2, 3, and 4 accordingly. Individual overall self-efficacy ranged from 0 to 56 .

\section{Procedure}

\section{Web-Based Education}

Starting on January 8, 2018, after informed consent forms were signed and received, participants completed the baseline survey $\left(\mathrm{T}_{0}\right)$. Individuals then engaged in 16 weeks of webbased education. The content was divided into 4 self-paced modules which focused on the Mediterranean Diet and lifestyle, healthy properties of Mediterranean staples, possible implications from following the Mediterranean lifestyle, and a contrast between the Mediterranean region and American health-related habits. Module content consisted of instructor generated videos, PowerPoints, required readings, and additional resources for further optional exploration. The semester ended in May, at which time participants completed the post-education survey $\left(\mathrm{T}_{1}\right)$.

\section{Cultural Immersion}

Two weeks after the end of the virtual education period, the group embarked on a 2-week cultural immersion experience through Tuscany, Italy for active hands on learning. In late May, individuals participated in tours of production facilities for common Mediterranean staples (i.e. wine, olive oil, cheese, ancient grains). The group heard from cultural experts, experienced traditional Italian meal time, and engaged in multiple culinary lessons at countryside homes and esteemed culinary schools. Upon return to the United States, two days after the trip's end, 
participants were sent the post-immersion survey $\left(\mathrm{T}_{2}\right)$. All responses were obtained within two weeks.

Follow-Up

Participants then returned to normal every day practice for a 7-month period. In January 2019, 1 year after the start of the intervention, individuals completed the follow up survey $\left(\mathrm{T}_{3}\right)$.

\section{Statistical Analysis}

Data were analyzed using JMP and SAS software (JMP®, Version Pro 12.2, SAS Institute Inc., Cary, NC, USA, Copyright (C2015; SAS®, Version 9.3, SAS Institute Inc., Cary, NC, USA, Copyright (C2002-2010). Survey responses were reported as ratings on ordinal item scales. Results are reported as means along side standard deviations. Response variables collected at each time point were analyzed via irregularly-spaced repeated measures analysis of variance (ANOVA). Data screening revealed a lack of normality and left-skewness, especially for the variables of knowledge and self-efficacy. The latter was corrected using a cube transformation, while $3 / 4$ of the knowledge time points remain left skewed. Mediterranean Diet Score, attitude, and cube transformed self-efficacy were compared to the baseline measure through Dunnett's multiple comparison testing. Knowledge data were analyzed via Cochran-Mantel-Haenszel testing, while controlling for subject, to assess correlation for this ordinally scaled item. In all statistical analyses, significance criterion alpha for all tests was 0.05 and a statistical trend was declared when $\mathrm{p}<0.1$.

\section{RESULTS}

\section{Demographics}

A total of 18 individuals enrolled in the study, of which 3 were excluded for not meeting inclusion criteria (i.e. practicing in a health professional field, willingness to participate in both the online education and travel abroad components, West Virginia resident, completion of informed consent). The final sample $(\mathrm{N}=15)$ was $73 \%$ female ranging from ages 22 to 65 (mean age: $43 \pm 16.92)$. Table 1 shows the sample breakdown by discipline.

Table 1. Breakdown of Sample Disciplines

\begin{tabular}{|l|l|l|}
\hline Discipline & Frequency (N) & Percent (\%) \\
\hline Nutrition & 5 & $33 \%$ \\
\hline Dental (total) & 3 & $20 \%$ \\
Dentist & 2 & $13 \%$ \\
Dental Hygienist & 1 & $7 \%$ \\
\hline Respiratory Therapy & 1 & $7 \%$ \\
\hline Psychology & 1 & $7 \%$ \\
\hline Nursing & 1 & $7 \%$ \\
\hline Health Department IT & 1 & $7 \%$ \\
\hline Life Coach & 1 & $7 \%$ \\
\hline Physician (total) & 2 & $13 \%$ \\
\hline
\end{tabular}




\begin{tabular}{|l|l|l|}
\hline Family & 1 & $7 \%$ \\
OBGYN & 1 & $7 \%$ \\
\hline
\end{tabular}

\section{Body Mass Index}

At baseline, the group had an average Body Mass Index (BMI) of $29.15 \pm 7.96 \mathrm{~kg} / \mathrm{m}^{2}$, followed by $26.85 \pm 5.21 \mathrm{~kg} / \mathrm{m}^{2}$ at $\mathrm{T}_{1}, 28.19 \pm 6.24 \mathrm{~kg} / \mathrm{m}^{2}$ at $\mathrm{T}_{2}$, and $28 \pm 5.88 \mathrm{~kg} / \mathrm{m}^{2}$ at $\mathrm{T}_{3}$.

\section{Mediterranean Diet Score}

Mediterranean Diet Score improved steadily from $12.6 \pm 3.09$ at $\mathrm{T}_{0}$ to $14.27 \pm 2.74$ at $\mathrm{T}_{1}$ and again to $15 \pm 2.33$ at $\mathrm{T}_{2}$. Mediterranean Diet Score then fell slightly during the 7 month return to practice, with participants reporting an average score of $14.5 \pm 2.93$ at $\mathrm{T}_{3}$. While differences in mean Mediterranean Diet Score between baseline and post-education, as well as baseline and follow up were not significantly different ( $\mathrm{p}=0.1191, \mathrm{p}=0.1849$ accordingly), mean Mediterranean Diet Score from baseline to post-immersion significantly improved $(p=0.0259)$.

\section{Nutrition Knowledge}

On the 0 to 8-point scale, average group knowledge fluctuated from $6.20 \pm 1.26$ at $\mathrm{T}_{0}$, $7.27 \pm 1.10$ at $\mathrm{T}_{1}, 7.13 \pm 0.83$ at $\mathrm{T}_{2}$, and $7.29 \pm 1.07$ at $\mathrm{T}_{3}$. More specifically, there was a 1.17point rise in knowledge score from baseline to post-education, a slight decrease in knowledge score (0.14-point deficit) after the immersion experience, and a 0.16-point increase upon follow up. The integers (1-8) were used to score the knowledge level for Cochran-Mantel-Haenszel statistics to assess mean scores and for the correlation statistic. When controlling for subject, the nonzero correlation statistic $(\mathrm{p}=0.0136)$ shows a highly significant monotone association between progression of days and knowledge level scores. The results from the means score statistic also show statistical significance for difference in means across the intervention $(\mathrm{p}=0.0075)$. Analysis revealed that there was significant $(\mathrm{p}=0.0325)$ shift in row mean scores, signifying that knowledge score is directly associated with time.

Attitudes

Participant attitudes increased across the study timeline. On the scale of $0-100$, average group attitudes were reported as $83.67 \pm 11.97$ at $\mathrm{T}_{0}, 86.8 \pm 7.97$ at $\mathrm{T}_{1}, 87.93 \pm 10.26$ at $\mathrm{T}_{2}$, and $91.57 \pm 5.96$ at $\mathrm{T}_{3}$. Attitude data were analyzed using repeated measures ANOVA with irregular spacing. Results from times $T_{0}, T_{1}$, and $T_{3}$ were normally distributed, while attitude scores at $T_{2}$ were left skewed. The repeated measures ANOVA was followed by Dunnett's multiple comparisons.

Table 2. Results of Dunnett's Multiple Comparisons Testing on Group Attitude

\begin{tabular}{|c|c|c|c|c|}
\hline Comparison & Estimate & $\begin{array}{c}\text { Standard } \\
\text { Error }\end{array}$ & $\begin{array}{c}\text { Degrees of } \\
\text { Freedom }\end{array}$ & Adjusted P \\
\hline $\mathrm{T}_{0}-\mathrm{T}_{1}$ & 3.1333 & 2.9340 & 41 & 0.5471 \\
\hline $\mathrm{T}_{0}-\mathrm{T}_{2}$ & 4.2667 & 3.1186 & 41 & 0.3631 \\
\hline $\mathrm{T}_{0}-\mathrm{T}_{3}$ & 7.8418 & 3.5425 & 41 & $0.0764^{\dagger}$ \\
\hline
\end{tabular}

Concise differences of least square means data results 
$\dagger_{p}<0.1$, trending

Results (Table 2) revealed no significant differences in group attitude from baseline to post-education, post-immersion, or follow up (all p-value's $>0.05$ ). However, there appears to be a statistical trend $(\mathrm{p}=0.0764)$ between baseline and follow up, during which time attitude increased 7.9-points on a scale of 0 to 100 .

\section{Self-Efficacy}

Individual overall self-efficacy ranged from 0 to 56 . Participants reported increasing levels of confidence: $34.6 \pm 13.80$ at $\mathrm{T}_{0}, 44.80 \pm 11.33$ at $\mathrm{T}_{1}, 47.13 \pm 9.55$ at $\mathrm{T}_{2}$, and $48.5 \pm 8.05$ at $\mathrm{T}_{3}$. Average self-efficacy at baseline was found to be significantly different from levels at all other time points. Self-efficacy data were analyzed using repeated measures ANOVA with irregular spacing. Data at baseline was normally distributed, while data for times $T_{1}, T_{2}$, and $T_{3}$ were left-skewed. A cube transformation was performed to correct these abnormal distributions. The repeated measures ANOVA was followed by Dunnett's multiple comparisons.

Table 3. Results of Dunnett's Multiple Comparisons Testing on Group Self-Efficacy

\begin{tabular}{|l|l|l|l|l|}
\hline Comparison & $\begin{array}{l}\text { Estimate } \\
\text { (cubed value) }\end{array}$ & $\begin{array}{l}\text { Standard Error } \\
\text { (cubed value) }\end{array}$ & $\begin{array}{l}\text { Degrees of } \\
\text { Freedom }\end{array}$ & Adjusted P \\
\hline $\mathrm{T}_{0}-\mathrm{T}_{1}$ & 45353 & 8440.24 & 41 & $<0.0001^{*}$ \\
\hline $\mathrm{T}_{0}-\mathrm{T}_{2}$ & 56646 & 9458.34 & 41 & $<0.0001^{*}$ \\
\hline $\mathrm{T}_{0}-\mathrm{T}_{3}$ & 60974 & 13740 & 41 & $0.0002^{*}$ \\
\hline
\end{tabular}

Concise differences of least square means data results

$* p<0.05$, statistical significance

Results (Table 3) show that average self-efficacy scores at post-education, postimmersion, and follow up were significantly different from average group self-efficacy at baseline with self-efficacy increasing a total of 13.9 points on a 56-point scale from first to last data collection.

\section{DISCUSSION}

The current study found that a "learn first, practice second" approach was effective in increasing the nutrition related knowledge and self-efficacy of currently practicing health professionals in West Virginia, with positively trending results for attitudes.

Overall, average sample knowledge score increased from baseline to follow up, although fluctuation occurred throughout the intervention. It can be speculated that the lack of nutrition information provided concretely to participants after the completion of the online course contributed to these changes. Participants had the curriculum at their disposal across time, however, reviewing the information was voluntary. Additionally, during the travel period, any education that occurred was delivered verbally, so retention may have been low. Overall, nutrition knowledge from baseline to post-immersion experienced a statistically significant increase, implying that the iCHOP Mediterranean intervention was successful in providing nutrition education. Other research supports the present findings that providing education and/or hands on learning can improve nutrition knowledge. Researchers from the University of 
Minnesota - Twin Cities found that a short-term education program and the inclusion of experiential skill building positively affected their population's food knowledge level ${ }^{26}$. Another study suggests that e-learning interventions can be helpful in improving nutrition knowledge among non-nutrition professionals ${ }^{27}$. Therefore, it may be advantageous for interventions aimed at improving nutrition knowledge to incorporate classroom and experiential learning opportunities.

Self-efficacy increased throughout the intervention, with some attribution to the concurrent increase in nutrition knowledge. As previously mentioned, exposing individuals to some form of education can result in a higher level of comfort with topics to facilitate behavior change $^{17}$. The less dramatic rises in self-efficacy at the latter two time points may be due to the fact that confidence increased so greatly upon the education period, that the hands-on practice reinforced rather than improved and this new level of confidence was strengthened when implementing new concepts and behaviors in participants' every day lives. Overall, this style intervention appears beneficial in increasing self-efficacy of West Virginia health professionals. That is, after undergoing nutrition education in addition to partaking in first hand experiences, confidence to incorporate Mediterranean principles into regular practice is higher. Results of the present study are consistent with other research that has shown how an online nutrition education intervention can be successful for improving self-efficacy for diet-related behavior change ${ }^{28}$. Additionally, Franko et al. found that self-efficacy is an important variable in health behavior change, and that a nutrition education website appeared beneficial for increasing the self-efficacy of participants ${ }^{29}$. Thus, using nutrition education to improve health practitioners' self-efficacy to engage patients in nutrition dialog may be beneficial.

Participants attitudes toward nutrition in medicine were increasingly positive as the study progressed although not significant. Perhaps this is due to the fact that the study subjects entered the intervention with already positive attitudes, which were not highly altered by the content but rather reinforced or solidified. This is consistent with other research that has shown how multidisciplinary health professionals recognize the importance of nutrition in health, with physicians vocalizing that nutrition counseling can have effects on behavior and referring patients to dietitians ${ }^{25}$. Additionally, current medical students have stated that they value nutrition education in their schooling for overall wellness and disease prevention yet lacked adequate knowledge to effectively counsel patients on recommendations ${ }^{30}$. Even more obscure health positions that may not seem directly related to nutrition in health, such as paramedics, seem positive about the role of proper nutrition. MacDonald et al. ${ }^{31}$ found that a sample of paramedics had positive attitudes both before and after the intervention, implicating that there is some level of appreciation and acknowledgement regarding the importance of dietary habits for wellness.

Although showing promise for the use of a learn first, practice second intervention, this study is not without limitations. First, the sample size of 15 participants may be thought to hinder precision or devalue the results. This number was chosen due to space restrictions for activities and accommodations abroad. While there are some drawbacks to a study with such a small sample, it allowed iCHOP Mediterranean to be completed in a timely manner and also acted as a feasibility study to test the potential outcomes of a certain intervention style. Based on the results, a similar study can be conducted on a larger sample or varying populations in order to capture more extensive data. Second, the present study has only been conducted in a small West Virginia population, and cannot be generalized to health practitioners in other states. Further research should test this intervention style in different locations. Third, the survey used to collect 
data at each time is not yet validated. The survey was constructed from a mix of other validated and not validated tools, but was built based on previous literature with the aims of the present study in mind. Researchers may work toward validation. Fourth, all data was self-reported. While researchers feel that the relationship with participants fostered honesty, it must be considered that there is room for false or misreported information.

Results from iCHOP Mediterranean show that a learn first, practice second style intervention can positively impact nutrition-related knowledge and self-efficacy, and could potentially improve attitudes toward nutrition in medicine. Findings from the present study are consistent with the literature, as evidenced by the contents of the introduction. On the basis of principles explained by the Social Cognitive Theory ${ }^{11}$, it is thought that by implementing an intervention, like that of iCHOP Mediterranean, in order to improve knowledge, attitude, and self-efficacy, researchers have the potential to facilitate behavior change. Further, by educating health professionals on incorporating healthy principles into their regular practice behavior and allowing them physical exposure to exemplar cultures, the health of the general population may be improved.

Future research should investigate further interventions such as a larger scale, including a wider array of health disciplines, or more specific cohorts within specific fields. Since the results regarding attitude toward nutrition in medicine were only trending toward statistical significance in the present study, further examination into what may influence an individual's attitude is needed. Additionally, it may prove beneficial to explore more exact components of nutrition education and experiential learning that influence knowledge, attitudes, and self-efficacy.

Overall, study findings suggest that iCHOP Mediterranean, a learn first, practice second style approach, may be beneficial in improving health practitioners' knowledge and self-efficacy regarding Mediterranean lifestyle principles. This feasibility study warrants further exploration in order to diversify multidisciplinary care and positively impact patient or client health.

Conflict of Interest: The authors declare no conflict of interest with any components of the present research.

\section{REFERENCES}

1. Polak, R., Phillips, E. M., Nordgren, J., La Puma, J., La Barba, J., Cucuzzella, M., ... \& Eisenberg, D. (2016). Health-related culinary education: A summary of representative emerging programs for health professionals and patients. Global advances in health and medicine, 5(1), 61-68.

2. Trichopoulou A, Martínez-González MA, Tong TY, et al. Definitions and potential health benefits of the Mediterranean diet: views from experts around the world. BMC Med. 2014;12:112.

3. CIHEAM/FAO. 2015. Mediterranean food consumption patterns: diet, environment, society, economy and health. a White Paper Priority 5 of Feeding Knowledge Programme, expo milan 2015. ciheam-iamB, Bari/Fao, rome.

4. Spronk, I., Kullen, C., Burdon, C., \& O'Connor, H. (2014). Relationship between nutrition knowledge and dietary intake. British Journal of Nutrition, 111(10), 1713-1726. 
5. Bonaccio M, Di Castelnuovo A, Costanzo S, et al. Nutrition knowledge is associated with higher adherence to Mediterranean diet and lower prevalence of obesity. Results from the Moli-sani study. Appetite. 2013;68:139-146.

6. Sharifirad G, Entezari MH, Kamran A, Azadbakht L. The effectiveness of nutritional education on the knowledge of diabetic patients using the health belief model. $J$ Res Med Sci. 2009;14(1):1-6.

7. Adams KM, Kohlmeier M, Zeisel SH. Nutrition education in U.S. medical schools: latest update of a national survey. Acad Med. 2010;85:1537-1542.

8. National Research Council. 1985, Nutrition Education in U.S. Medical Schools. Washington, DC: The National Academies Press. https://doi.org/10.17226/597.

9. Parker WA, Steyn NP, Levitt NS, Lombard CJ. They think they know but do they? Misalignment of perceptions of lifestyle modification knowledge among health professionals. Public Health Nutr. 2011;14:1429-1438.

10. Barratt J. Diet-related knowledge, beliefs and actions of health professionals compared with the general population: an investigation in a community Trust. J Hum Nutr Diet. 2001;14:25-32.

11. Bandura, A. (2011). Social cognitive theory. Handbook of social psychological theories, 2012, 349-373.

12. Guntzviller LM, King AJ, Jensen JD, Davis LA. Self-efficacy, health literacy, and nutrition and exercise behaviors in a low-income, hispanic population. Journal of immigrant and minority health. 2017;19(2):489-493. doi:10.1007/s10903-016-0384-4

13. Adam J, Folds L. Depression, self-efficacy, and adherence in patients with type 2 diabetes. The journal for nurse practitioners. 2014;10(9):646-652. doi:10.1016/j.nurpra.2014.07.033

14. Prochaska, J. O. (2013). Transtheoretical model of behavior change. In Encyclopedia of behavioral medicine (pp. 1997-2000). Springer, New York, NY.

15. Wynn, K., Trudeau, J. D., Taunton, K., Gowans, M., \& Scott, I. (2010). Nutrition in primary care: current practices, attitudes, and barriers. Canadian family physician, 56(3), e109e116.

16. Assessment of Nutrition Knowledge and Attitudes in Preclinical Osteopathic Medical Students.J Am Osteopath Assoc. 2017 Oct 1;117(10):622-633. doi: 10.7556/jaoa.2017.119.

17. McGaghie WC, Issenberg SB, Cohen ER, Barsuk JH, Wayne DB. Does simulation-based medical education with deliberate practice yield better results than traditional clinical education? A meta-analytic comparative review of the evidence. Acad Med. 2011;86(6):706-11.

18. Zink, T., Halaas, G. W., Finstad, D., \& Brooks, K. D. (2008). The rural physician associate program: the value of immersion learning for third-year medical students. The Journal of Rural Health, 24(4), 353-359.

19. Tremethick, M. J., \& Smit, E. M. (2009). Preparing culturally competent health educators: The development and evaluation of a cultural immersion service-learning program. International Electronic Journal of Health Education, 12, 185-193.

20. Hagedorn R, Morris A, Clark R, Harris B, George A, Enfonde J, Brubaker D, Olfert M. Knowledge, Attitudes, and Self-Efficacy of Culinary Skills as they Relate to Chronic Disease Prevention in 
Future Health Practitioners: iCHOP Pilot Study. Journal of Nutrition Education and Behavior. 2017 Jul 1;49(7):S77.

21. Serra-Majem L, Ribas L, Ngo J, Ortega RM, Garcia A, Pérez-Rodrigo C, Aranceta J. Food, youth and the Mediterranean Diet in Spain. Development of KIDMED, Mediterranean Diet Quality Index in children and adolescents. Public Health Nutrition 2004; 7(7):931935.

22. Sotos-Prieto, M., Moreno-Franco, B., Ordovás, J. M., León, M., Casasnovas, J. A., \& Peñalvo, J. L. (2015). Design and development of an instrument to measure overall lifestyle habits for epidemiological research: the Mediterranean Lifestyle (MEDLIFE) index. Public health nutrition, 18(6), 959-967.

23. Willett, W. C., Sacks, F., Trichopoulou, A., Drescher, G., Ferro-Luzzi, A., Helsing, E., \& Trichopoulos, D. (1995). Mediterranean diet pyramid: a cultural model for healthy eating. The American journal of clinical nutrition, 61(6), 1402S-1406S.

24. McGaghie, William C et al. Development of a measure of attitude toward nutrition in patient care. American Journal of Preventive Medicine, Volume 20 , Issue 1, 15 - 20.

25. Mihalynuk TV, Scott CS, Coombs JB. Self-reported nutrition proficiency is positively correlated with the perceived quality of nutrition training of family physicians in Washington State. Am J Clin Nutr. 2003;77:1330-1336.

26. Rustad, C., \& Smith, C. (2013). Nutrition knowledge and associated behavior changes in a holistic, short-term nutrition education intervention with low-income women. Journal of nutrition education and behavior, 45(6), 490-498.

27. Sharma, Priya \& M. Usha Rani (2016) Effect of Digital Nutrition Education Intervention on the Nutritional Knowledge Levels of Information Technology Professionals, Ecology of Food and Nutrition, 55:5, 442-455, DOI: 10.1080/03670244.2016.1207068

28. Poddar, K. H., Hosig, K. W., Anderson, E. S., Nickols-Richardson, S. M., \& Duncan, S. E. (2010). Web-based nutrition education intervention improves self-efficacy and selfregulation related to increased dairy intake in college students. Journal of the American Dietetic Association, 110(11), 1723-1727.

29. Franko, D. L., Cousineau, T. M., Trant, M., Green, T. C., Rancourt, D., Thompson, D., ... \& Ciccazzo, M. (2008). Motivation, self-efficacy, physical activity and nutrition in college students: Randomized controlled trial of an internet-based education program. Preventive medicine, 47(4), 369-377.

30. Adams, K. M., Kohlmeier, M., Powell, M., \& Zeisel, S. H. (2010). Nutrition in medicine: nutrition education for medical students and residents. Nutrition in clinical practice : official publication of the American Society for Parenteral and Enteral Nutrition, 25(5), 471-80.

31. MacDonald, Amanda B,B.Sc, R.D., Jensen, Jan L,M.A.H.S.R., A.C.P., and Melissa D. Rossiter PhD. "Nutrition and Shiftwork: Evaluation of New Paramedics' Knowledge and Attitudes." Canadian Journal of Dietetic Practice and Research74.4 (2013): 198201. ProQuest. Web. 2 Dec. 2018. 


\section{Overall Thesis Document References}

1. La Puma, J. (2016). What is culinary medicine and what does it do?. Population health management, 19(1), 1-3.

2. CIHEAM/FAO. (2015). A White Paper Priority 5 of Feeding Knowledge. Mediterranean food consumption patterns: diet, environment, society, economy and health.

3. Trichopoulou, A., Martínez-González, M. A., Tong, T. Y., Forouhi, N. G., Khandelwal, S., Prabhakaran, D., ... \& de Lorgeril, M. (2014). Definitions and potential health benefits of the Mediterranean diet: views from experts around the world. BMC medicine, 12(1), 112.

4. Blue Zones. The Original "Blue Zones". Blue Zones website. https://bluezones.com/livelonger-better/original-blue-zones/\#section-1.

5. World Health Organization. (2017, October) Obesity and Overweight. World Health Organizationwebsite. http://www.who.int/mediacentre/factsheets/fs311/en/.

6. Bonaccio, M., Di Castelnuovo, A., Costanzo, S., De Lucia, F., Olivieri, M., Donati, M. B., ... \& Moli-sani Project Investigators. (2013). Nutrition knowledge is associated with higher adherence to Mediterranean diet and lower prevalence of obesity. Results from the Moli-sani study. Appetite, 68, 139-146.

7. National Research Council. (1985). Nutrition education in US medical schools. National Academies Press.

8. Adams, K. M., Kohlmeier, M., \& Zeisel, S. H. (2010). Nutrition education in US medical schools: latest update of a national survey. Academic medicine: journal of the Association of American Medical Colleges, 85(9), 1537.

9. Parker, W. A., Steyn, N. P., Levitt, N. S., \& Lombard, C. J. (2011). They think they know but do they? Misalignment of perceptions of lifestyle modification knowledge among health professionals. Public health nutrition, 14(8), 1429-1438.

10. Barratt, J. (2001). Diet-related knowledge, beliefs and actions of health professionals compared with the general population: an investigation in a community Trust. Journal of Human Nutrition and Dietetics, 14(1), 25-32.

11. Zappalà, G., Buscemi, S., Mulè, S., La Verde, M., D’Urso, M., Corleo, D., \& Marranzano, M. (2017). High adherence to Mediterranean diet, but not individual foods or nutrients, is associated with lower likelihood of being obese in a Mediterranean cohort. Eating and Weight Disorders-Studies on Anorexia, Bulimia and Obesity, 1-10.

12. Estruch, R., Ros, E., Salas-Salvadó, J., Covas, M. I., Corella, D., Arós, F., ... \& LamuelaRaventos, R. M. (2013). Primary prevention of cardiovascular disease with a Mediterranean diet. New England Journal of Medicine, 368(14), 1279-1290.

13. Martínez-González, M. Á., De la Fuente-Arrillaga, C., Nunez-Cordoba, J. M., BasterraGortari, F. J., Beunza, J. J., Vazquez, Z., ... \& Bes-Rastrollo, M. (2008). Adherence to Mediterranean diet and risk of developing diabetes: prospective cohort study. Bmj, 336(7657), 1348-1351.

14. Barak, Y., \& Fridman, D. (2017). Impact of mediterranean diet on cancer: Focused literature review. Cancer Genomics-Proteomics, 14(6), 403-408.

15. Martínez-González, M. A., \& Sánchez-Villegas, A. (2016). Food patterns and the prevention of depression. Proceedings of the Nutrition Society, 75(2), 139-146.

16. Kolodinsky, J., Harvey-Berino, J. R., Berlin, L., Johnson, R. K., \& Reynolds, T. W. (2007). Knowledge of current dietary guidelines and food choice by college students: 
better eaters have higher knowledge of dietary guidance. Journal of the american Dietetic Association, 107(8), 1409-1413.

17. Lin, W., Hang, C. M., Yang, H. C., \& Hung, M. H. (2011). 2005-2008 Nutrition and Health Survey in Taiwan: the nutrition knowledge, attitude and behavior of 19-64 years old adults. Asia Pacific journal of clinical nutrition, 20(2), 309-318.

18. Grosso, G., Mistretta, A., Turconi, G., Cena, H., Roggi, C., \& Galvano, F. (2013). Nutrition knowledge and other determinants of food intake and lifestyle habits in children and young adolescents living in a rural area of Sicily, South Italy. Public health nutrition, 16(10), 1827-1836.

19. Pirouznia, M. (2001). The association between nutrition knowledge and eating behavior in male and female adolescents in the US. International journal of food sciences and nutrition, 52(2), 127-132.

20. Kristjansdottir, A. G., Thorsdottir, I., De Bourdeaudhuij, I., Due, P., Wind, M., \& Klepp, K. I. (2006). Determinants of fruit and vegetable intake among 11-year-old schoolchildren in a country of traditionally low fruit and vegetable consumption. International Journal of Behavioral Nutrition and Physical Activity, 3(1), 41.

21. Adams, K. M., Kohlmeier, M., Powell, M., \& Zeisel, S. H. (2010). Nutrition in medicine: nutrition education for medical students and residents. Nutrition in Clinical Practice, 25(5), 471-480.

22. Vetter, M. L., Herring, S. J., Sood, M., Shah, N. R., \& Kalet, A. L. (2008). What do resident physicians know about nutrition? An evaluation of attitudes, self-perceived proficiency and knowledge. Journal of the American College of Nutrition, 27(2), 287298.

23. Bandura, A. (2011). Social cognitive theory. Handbook of social psychological theories, 2012, 349-373.

24. Anderson-Bill, E. S., Winett, R. A., \& Wojcik, J. R. (2011). Social cognitive determinants of nutrition and physical activity among web-health users enrolling in an online intervention: The influence of social support, self efficacy, outcomes expectations, and self-regulation. Journal of medical Internet research.

25. Schwarzer, R. (2014). Self-efficacy: Thought control of action. Taylor \& Francis.

26. Wynn, K., Trudeau, J. D., Taunton, K., Gowans, M., \& Scott, I. (2010). Nutrition in primary care: current practices, attitudes, and barriers. Canadian family physician, 56(3), e109-e116.

27. Hargrove, E. J., Berryman, D. E., Yoder, J. M., \& Beverly, E. A. (2017). Assessment of nutrition knowledge and attitudes in preclinical osteopathic medical students. J. Am. Osteopath. Assoc, 117, 622-633.

28. Macdonald, A. B., Jensen, J. L., \& Rossiter, M. D. (2013). Nutrition and Shiftwork: Evaluation of New Paramedics' Knowledge and Attitudes. Canadian Journal of Dietetic Practice and Research, 74(4), 198-201.

29. McGaghie, W. C., Issenberg, S. B., Cohen, M. E. R., Barsuk, J. H., \& Wayne, D. B. (2011). Does simulation-based medical education with deliberate practice yield better results than traditional clinical education? A meta-analytic comparative review of the evidence. Academic medicine: journal of the Association of American Medical Colleges, 86(6), 706. 
30. Fast Facts, WV Department of Health and Human Resources, dhhr.wv.gov/hpcd/data_reports/pages/fast-facts.aspx.

31. Amarasinghe, A., D’Souza, G., Brown, C., Oh, H., \& Borisova, T. (2009). The influence of socioeconomic and environmental determinants on health and obesity: a West Virginia case study. International Journal of Environmental Research and Public Health, 6(8), 2271-2287.

32. Harris, C. V., \& Neal, W. A. (2009). Assessing BMI in West Virginia schools: parent perspectives and the influence of context. Pediatrics, 124(Supplement 1), S63-S72.

33. Meacham, S. L., Meisha, D., Woolley, S. M., Balmert, L. C., Talbott, E. O., Buchanich, J. M., \& Snyder, A. (2015, January). Social Determinants of Health Impacting Obesity, Diabetes Mellitus and Death Due to Injury in West Virginia and Virginia Coal Counties. In 2nd Environmental Considerations in Energy Production Conference (pp. 153-161). Society for Mining, Metallurgy and Exploration (SME).

34. Papadopoulos, I., Tilki, M., \& Ayling, S. (2008). Cultural competence in action for CAMHS: Development of a cultural competence assessment tool and training programme. Contemporary Nurse, 28(1-2), 129-140.

35. Lohse, B., Satter, E., Horacek, T., Gebreselassie, T., \& Oakland, M. J. (2007). Measuring eating competence: psychometric properties and validity of the ecSatter Inventory. Journal of Nutrition Education and Behavior, 39(5), S154-S166.

36. McGaghie, W. C., Van Horn, L., Fitzgibbon, M., Telser, A., Thompson, J. A., Kushner, R. F., \& Prystowsky, J. B. (2001). Development of a measure of attitude toward nutrition in patient care. American Journal of preventive medicine, 20(1), 15-20.

37. Mihalynuk, T. V., Scott, C. S., \& Coombs, J. B. (2003). Self-reported nutrition proficiency is positively correlated with the perceived quality of nutrition training of family physicians in Washington State. The American journal of clinical nutrition, 77(5), 1330-1336.

38. Serra-Majem, L., Ribas, L., Ngo, J., Ortega, R. M., García, A., Pérez-Rodrigo, C., \& Aranceta, J. (2004). Food, youth and the Mediterranean diet in Spain. Development of KIDMED, Mediterranean Diet Quality Index in children and adolescents. Public health nutrition, 7(7), 931-935.

39. Sotos-Prieto, M., Moreno-Franco, B., Ordovás, J. M., León, M., Casasnovas, J. A., \& Peñalvo, J. L. (2015). Design and development of an instrument to measure overall lifestyle habits for epidemiological research: the Mediterranean Lifestyle (MEDLIFE) index. Public health nutrition, 18(6), 959-967.

40. Stokes, M. E., C. S. Davis and G. G. Koch. 2012. Categorical Data Analysis using SAS,

41. Rustad, C., \& Smith, C. (2013). Nutrition knowledge and associated behavior changes in a holistic, short-term nutrition education intervention with low-income women. Journal of nutrition education and behavior, 45(6), 490-498.

42. Sharma, P., \& Rani, M. U. (2016). Effect of Digital Nutrition Education Intervention on the Nutritional Knowledge Levels of Information Technology Professionals. Ecology of food and nutrition, 55(5), 442-455.

43. Poddar, K. H., Hosig, K. W., Anderson, E. S., Nickols-Richardson, S. M., \& Duncan, S. E. (2010). Web-based nutrition education intervention improves self-efficacy and selfregulation related to increased dairy intake in college students. Journal of the American Dietetic Association, 110(11), 1723-1727. 
44. Franko, D. L., Cousineau, T. M., Trant, M., Green, T. C., Rancourt, D., Thompson, D., ... \& Ciccazzo, M. (2008). Motivation, self-efficacy, physical activity and nutrition in college students: Randomized controlled trial of an internet-based education program. Preventive medicine, 47(4), 369-377. 


\section{Appendices}

Appendix A: Comprehensive list of West Virginia professional organizations contacted during recruitment phase 1 .

- WV Society of Health System Pharmacists

- WV State Medical Association

- WV Osteopathic Medicine Association

- WV Academy of Family Physician Members

- WV Nurses Association

- WV Advanced Practice Registered Nurse Congress

- WV Physical Therapy Association

- WV Psychological Association

- WV Pharmacists Association

- WV Society for Respiratory Care

- National Association of Social Workers, WV Chapter

- WV Hospital Association

- WV College of Emergency Physicians

Appendix B: Recruitment Email

\section{(Insert association name here)!}

We would like to invite practicing to explore culinary Italy by way of a West Virginia University online course and travel abroad opportunity. By participating in online coursework throughout the Spring, and joining us on a 2-week trip to Tuscany, Italy at the end of May, you'll receive Mediterranean Diet focused education, culinary training, cultural immersion, and 3 credits of 400/500 level coursework.

Please forward this great opportunity to your professional association members (flyer attached). Please note that this is a multidisciplinary study, so participation in this experience is also an opportunity to interact with other professionals across a spectrum of health disciplines.

Increasing Culinary Health Opportunities for Professionals (iCHOP): Mediterranean Study offers you a one-of-a-kind culinary adventure? You are contributing to the investigation of the implementing culinary medicine into active practitioners. We hope that by the end of your experience, you feel empowered to use a Mediterranean approach in disease treatment and prevention, while sharing your experiences with others.

Please view the informational flyers attached to this email for more information. You can also go to bit.ly/ichopwvuabroad which contains program information and application instructions. Additionally, we will be holding info sessions on the West Virginia University. Follow this link bit.ly/ichopmed to sign up.

Thank you and we hope to hear from you soon!

Grazie. 


\section{Explore Culinary Italy}

\section{Attention health care professionals in West Virginia}

Doctors, Physician Assistants, Nurses, Nurse Practitioners, Dietitians, Dentists, Pharmacists. Physical Therapists. Occupational Therapists, Psychologists.

INFO SESSIONS IN MORGANTOWN OCT 8, 10 \& 142017 AT 6PM ONLINE COURSE DATES JAN 8 - MAY 92018 TRAVEL DATES MAY 21 - JUNE 32018

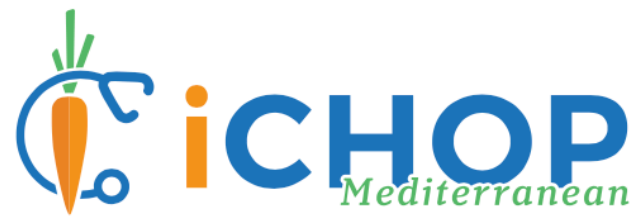

WVU is increasing culinary health opportunities for professionals (iCHOP) by introducing a course that focuses on nutrition knowledge, culinary skills, and Mediterranean diet culture. ending with a 14-day immersion experience in Tuscany, Italy. As part of a research study, the program aims to examine the use of culinary medicine among health professionals practicing in West Virginia.

\section{\$2900 TUITION FOR 3 CREDIT}

$\$ 2900$ UPPER LEVEL COURSE

INCLUDES AND 14 DAY TRAVEL AIRFARE NOT INCLUDED

Apply Today! Limited spots available.

D SIGN UP HERE BIT.LY/ICHOPWVUABROAD

$\checkmark$ REGISTER FOR AN INFO SESSION HERE BIT.LY/ICHOPMED

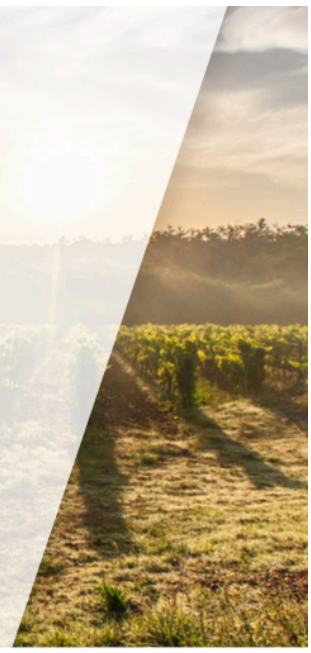

The course will provide health professionals with a toolkit that combines nutritional and cultural knowledge with increased culinary skills from experiential learning.

- Stay at local farm houses

- Visit vineyards

- Hunt for truffles

- Tend to bees

- Tour production facilities

for wine, cheese, olive oil and ancient grains

- Interactive culinary

trainings

and more

1. Understand nutritional components and

health benefits of Mediterranean cuisine

2. Study differences in Italian and American food and health systems

3. Application of learned skills and knowledge in practice

Appendix D: Web Links to Online Components of Recruitment

Recruitment Video: https://www.youtube.com/watch?v=TlfUWdgHtN0\&feature=youtu.be Office of Global Affairs Page: https://wvuabroad.wvu.edu/sites/index.cfm?FuseAction=Programs.ViewProgram\&Program ID= 10253 
Preliminary Screening Tool: https://wvu.qualtrics.com/jfe/form/SV cPbDJWjlh3eP4sl

Appendix E: Intervention Timeline

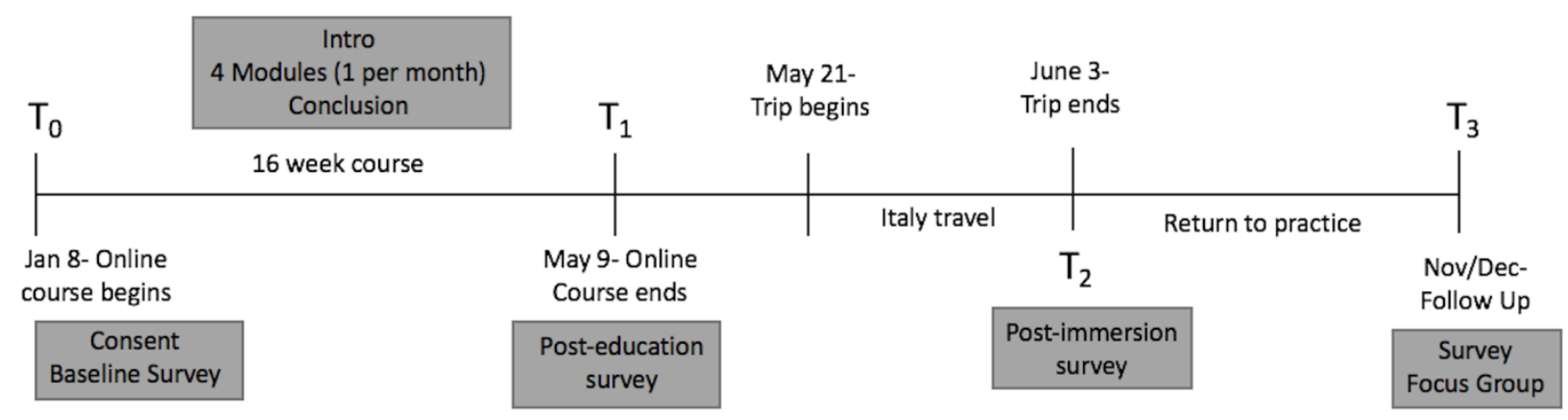

Appendix F: Survey

Demographics

Q1.1 Research subject number

Q1.2 Please self report the following data:

Height (inches) (1)

Weight (pounds) (2)

Q1.3 Do you participate in regular physical activity?

Yes. Please explain the type and frequency: (1)

No (2)

Attitude

Q1.10 Please rank how you feel about the following statements.
Disagree
Agree
$\begin{array}{lllllllllll}0 & 1 & 2 & 3 & 4 & 5 & 6 & 7 & 8 & 9 & 10\end{array}$ 


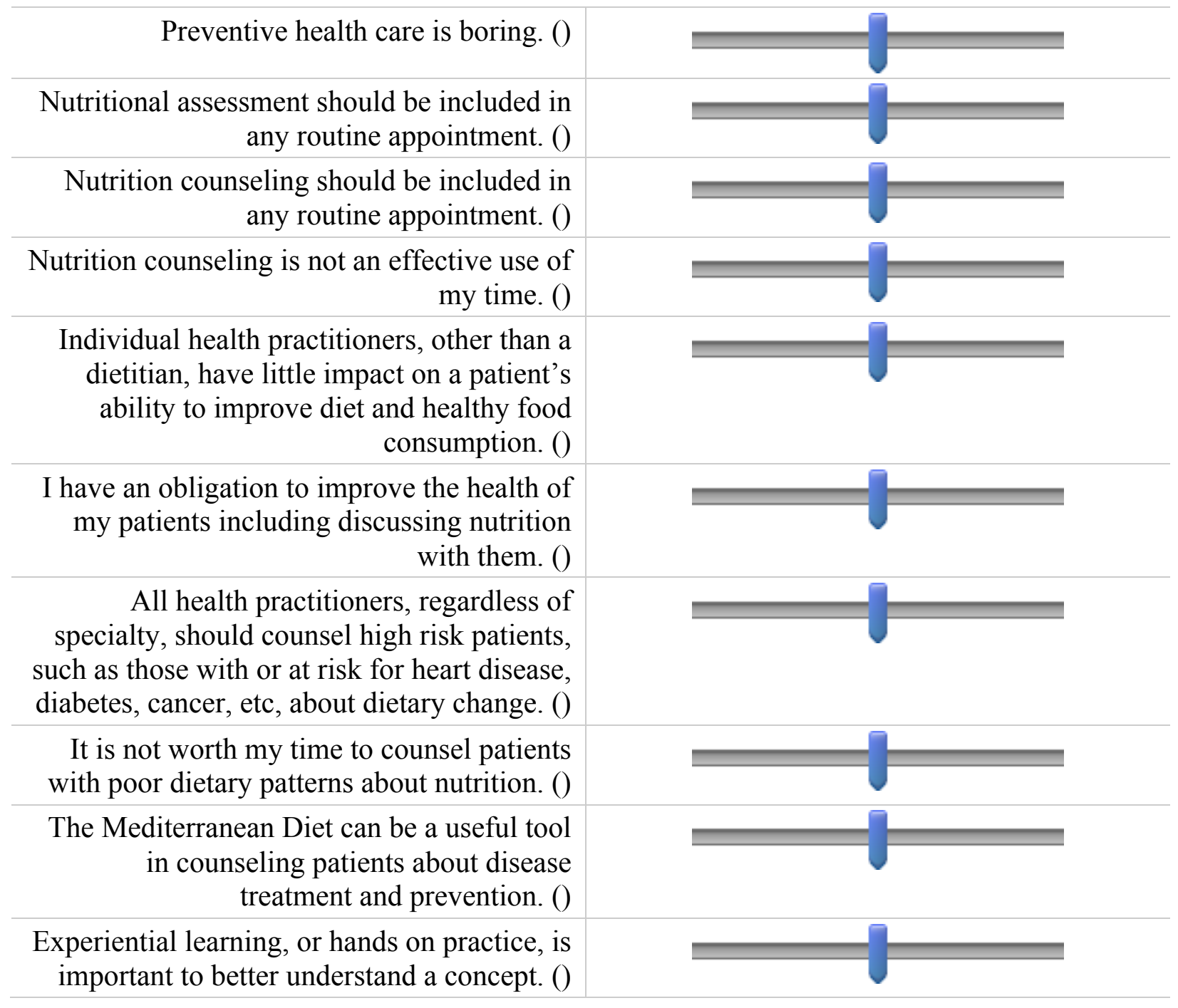

\section{$\underline{\text { Self-Efficacy }}$}

Q1.11 How comfortable do you feel in terms of your level of nutrition knowledge or counseling skills in the following areas?

$\begin{array}{ccccc}\begin{array}{c}\text { Not } \\ \text { Applicable }\end{array} & \begin{array}{c}\text { Not } \\ \text { Proficient }\end{array} & \begin{array}{c}\text { Somewhat } \\ \text { Proficient }\end{array} & \begin{array}{c}\text { Totally } \\ \text { Proficient }\end{array} \\ 0 & 1 & 2 & 3 & 4\end{array}$


Strategies, prevention, and treatment, including nutrition and lifestyle (1)

MyPlate Guide (2)

Mediterranean diet components (3)

The Mediterranean Diet Pyramid (4)

Mediterranean diet benefits (5)

Nutrition education for a patient with diabetes

(6)

Nutrition education for a patient with CVD

(7)

Calories per gram of protein, carbohydrate, and fat and their basic metabolic roles (8)

Calculation and explanation of Body Mass Index (BMI) (9)

Sources of specific vitamins and minerals

(10)

Serving sizes / MyPlate recommendations

(11)

Role of food constituents in health (fiber, soy, phytonutrients, antioxidants) (12)

Role of omega-3 and omega- 6 fatty acids in health (13)

Discussing culinary skills and various food preparation methods (14)
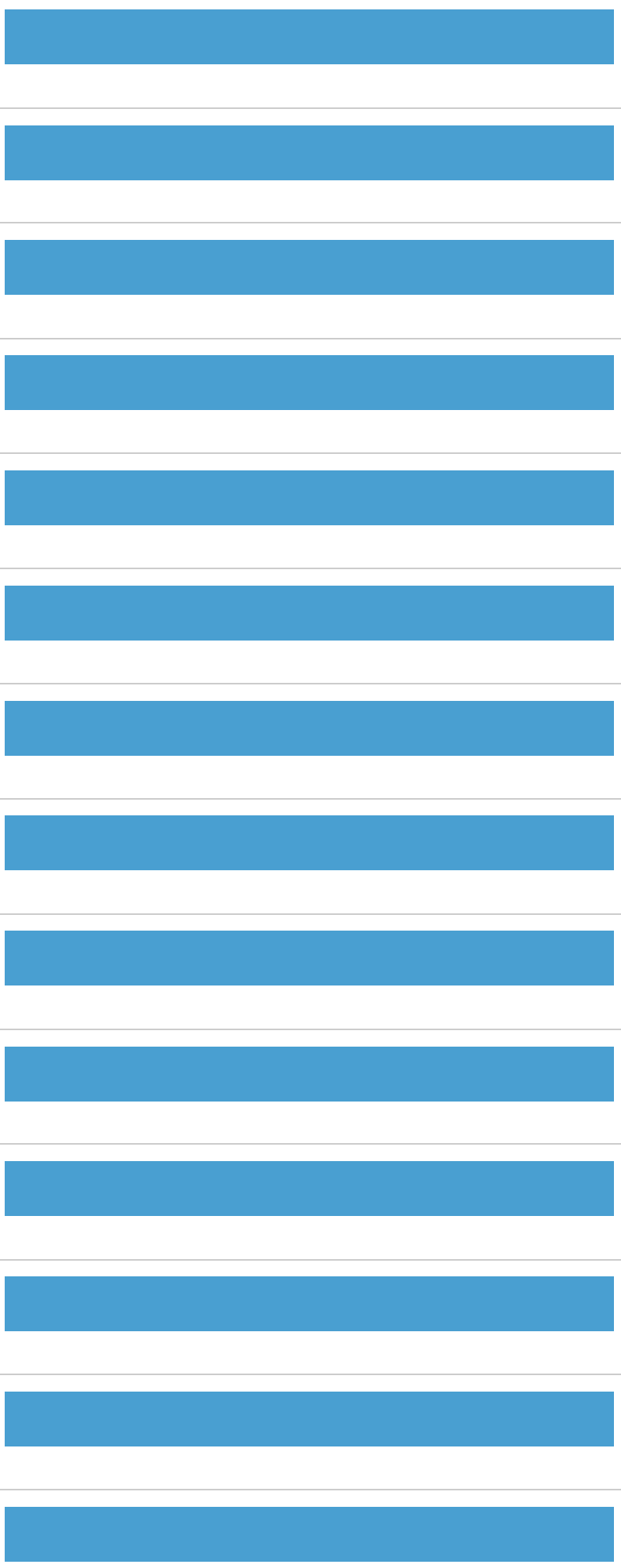

\section{Knowledge}

Q1.12 Which type of fat is prominent in the Mediterranean Diet, associating it with good heart health? 
Saturated Fats (1)

Unsaturated Fats (2)

Trans Fats (3)

Elimination of fat from the diet (4)

Q1.13 Which of the following is not a source of monounsaturated fat?

Olives (1)

Tomatoes (2)

Nuts (3)

Avocados (4)

Q1.14 If adhering to a Mediterranean diet pattern, which item should be consumed least?

Seafood (1)

Red meat (2)

Poultry (3)

Eggs (4)

Q1.15 According to the Mediterranean Diet Pyramid, which option should be the basis for every main meal?

Whole grains and protein (1)

Unsaturated fats and fruits/vegetables (2)

Dairy and protein (3)

Fruits/vegetables and whole grains (4) 
Q1.16 Which of the following is considered a healthy alcoholic drink due to its positive effects in lowering heart disease?

White wine (1)

Red wine (2)

Beer (3)

Spirits (4)

Q1.17 True or False: While the American food pyramid has evolved into the MyPlate diagram that depicts appropriate portions sizes, the Mediterranean Diet Pyramid has kept its layout in demonstrating how often certain foods should be consumed.
True (1)
False (2)

Q1.18 The Mediterranean Diet has shown positive health outcomes for which of the following health conditions? Mark all that apply.

\section{Cancer (1)}

Diabetes (2)

Cardiovascular Disease (3)

Mental Illness (4)

Metabolic Syndrome factors (5)

Alzheimer's (6) 
Q1.19 What is the name associated with the movement that promotes local, traditional foods as an alternative to processed items and fast food establishments?

Slow Food Movement (1)

Go Slow Movement (2)

Keep It Local (3)

Let's Grow (4)

Practice Behavior

Q1.20 Please rate your feelings for the following statements on a scale of 0-10, with zero being not at all important and ten being extremely important.

It is important that I perform some level of nutritional assessment with every patient ()

It is important that I address the importance of diet whenever I care for a patient ()

It is important that I assess each patient's weight status in accordance with the National

Institutes of Health guidelines on the identification, evaluation, and treatment of overweight and obesity in adults ()

It is important that I collaborate with a registered dietitian in my practice to achieve optimal treatment and prevention outcomes ()

It is important that I refer patients with dietrelated problems to a registered dietitian or other qualified nutrition staff ()

It is important that I recommend dietary changes before initiating drug therapy, whenever it is possible ()

It is important that I advocate a Mediterranean style diet to all patients ()

It is important that I advocate a Mediterranean style diet to patients at risk or
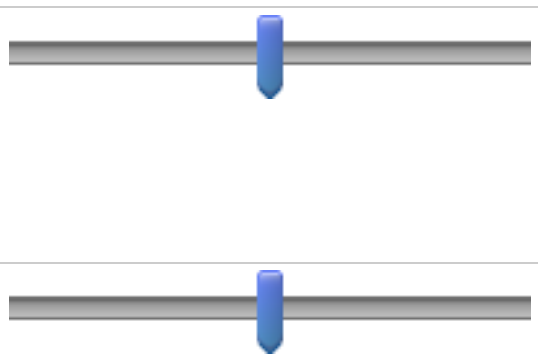
suffering from chronic disease () 
Patient Relationship

Q1.21 Patient motivation is essential to achieving dietary change

Agree (1)

Disagree (2)

Uncertain (3)

Prefer not answer (4)

Q1.22 Patients need good-tasting alternatives in order to change their eating patterns

Agree (1)

Disagree (2)

Uncertain (3)

Prefer not answer (4)

Q1.23 Most physicians are not adequately trained to discuss nutrition with patients

Agree (1)

Disagree (2)

Uncertain (3)

Prefer not answer (4) 
Q1.24 Patients need ongoing counseling to maintain behavior changes consistent with a healthier diet
Agree (1)
Disagree (2)
Uncertain (3)
Prefer not answer (4)

Q1.25 Any health professional can have an effect on a patient's dietary behavior if they take the time to discuss the problem

Agree (1)

Disagree (2)

Uncertain (3)

Prefer not answer (4)

Counseling Behavior

Q1.26 Have you heard of motivational interviewing?

Yes (1)

No (2)

\section{Skip To: Q1.29 If Have you heard of motivational interviewing? = No}

Display This Question:

If Have you heard of motivational interviewing? = Yes 
Q1.27 Do you understand the basic ideas and principles of motivational interviewing?

Yes (1)

Somewhat (2)

Uncertain (3)

Not really (4)

No (5)

\section{Display This Question:}

If Have you heard of motivational interviewing? = Yes

Q1.28 Do you feel that motivational interviewing is applicable to your work?

Yes (1)

No (2)

Unsure (3)

Q1.29 Do you feel that some clients will never change regardless of how you interact with them?

Yes (1)

Somewhat (2)

Uncertain (3)

Not really (4)

No (5) 
Q1.30 Rate how confident you feel in the following areas during patient interactions.

Not SomewhatConfident More Highly ConfidentConfident

than Confident

Confident

$\begin{array}{llllll}0 & 1 & 2 & 3 & 4 & 5\end{array}$


Discussing reasons for seeking counseling (1)

Using nonverbal communication (2)

Emphasizing small incremental changes (3)

$$
\text { Identifying support (4) }
$$

\begin{tabular}{r} 
Praising the positives (5) \\
\hline Collaborating with your client to establish \\
goals (6)
\end{tabular}

Sharing similar stories or examples (7)

Providing relevant data, facts, and resources for unbiased education (8)

Discussing your client's relationship with a dietitian (9)

Recommending that your client visit a dietitian (10)

Identifying barriers to change (11)

Disclosing yourself (12)

Evaluating ability to change (13)
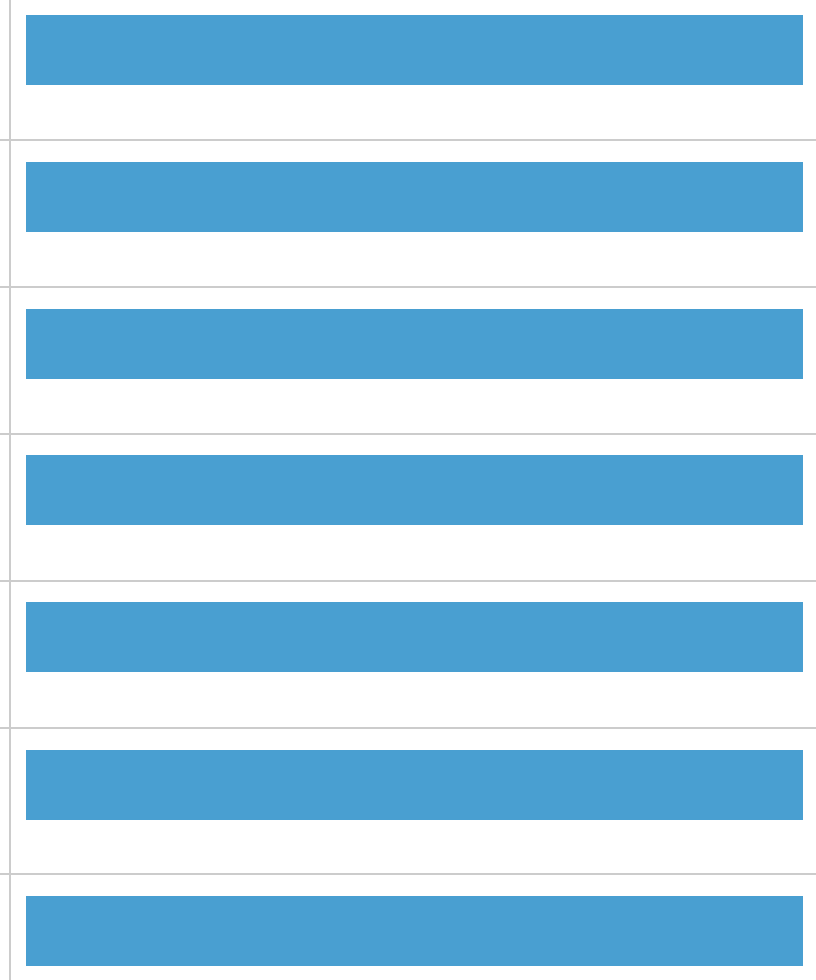

Readiness to Change

Q1.31 Please rate your readiness to perform each of the following actions. 


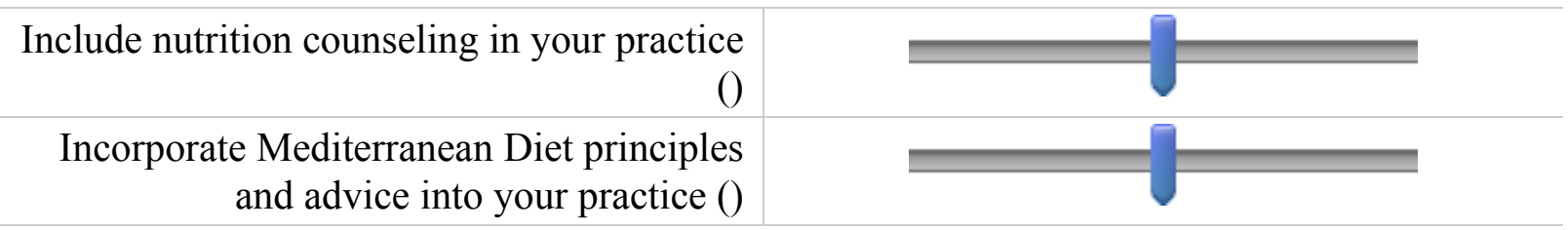

\section{Culinary Competence}

Q1.32 How would you rate yourself in each category?

Not

Not Somewhat Totally

Applicable Proficient Proficient Proficient

0

1

2

3

Preparing meals from scratch (1)

Knife skills (2)

Combining different foods together to make one cohesive item, plate, or meal (3)

\section{Family meals (4)}

Gardening/ Growing own produce (5)
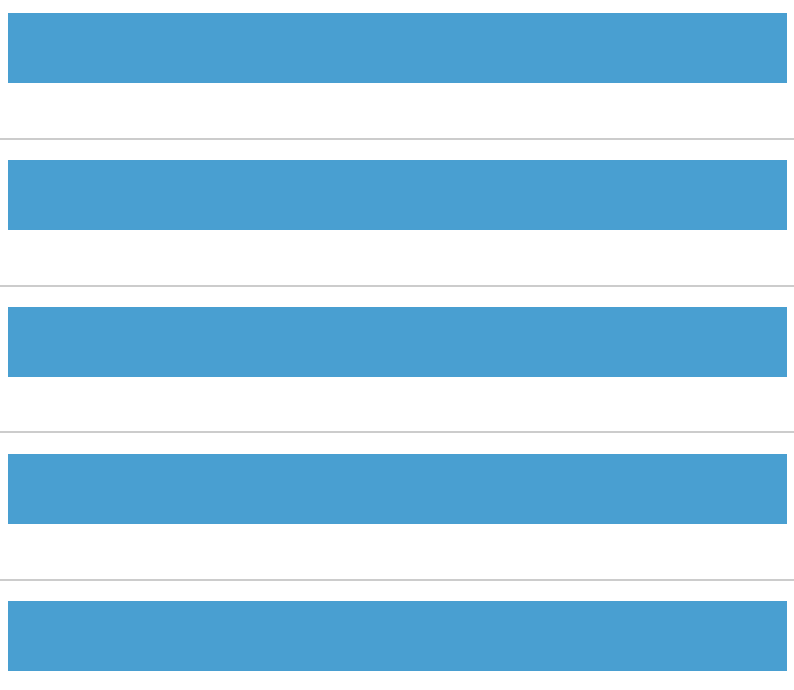

Cultural Competence

Q1.33 Please mark how often each of the following statements applies to you.

Never Sometimes $\begin{gathered}\text { Fairly Always } \\ \text { Often }\end{gathered}$

$\begin{array}{lllll}0 & 1 & 2 & 3 & 4\end{array}$


I view differences among humans as positive

(1)

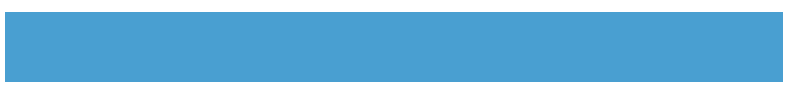

I have a clear sense of my personal ethnic identity (2)

I am aware of any assumptions that I hold about cultures other than my own (3)

I am aware of my cultural perspective and how it influences the behaviors and values that I deem 'appropriate', 'normal', or 'superior' (4)

I put myself in situations where I can experience cultures other than my own (5)

I recognize that my knowledge of some cultural groups is limited (6)

I work to understand others' perspectives when interacting with patients and colleagues

Eating Competence

Q1.34 Please mark how often each of the following statements applies to you.

Never Fairly Sometimes Often Always Often

0

1

2

3

4 
I feel it is okay to eat food that I like (5)

I experiment with new food and learn to like

it (6)

If the situation demands, I can "make do" by eating food I don't much care for (7)

I eat a variety of foods (8)

I assume I will get enough to eat (9)

I eat as much as I am hungry for (10)

I eat until I am satisfied (11)

I tune into food and pay attention to myself when I eat (12)

I make time to eat (13)

I have regular meals (14)

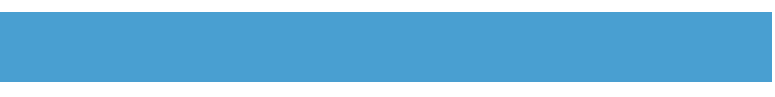

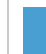
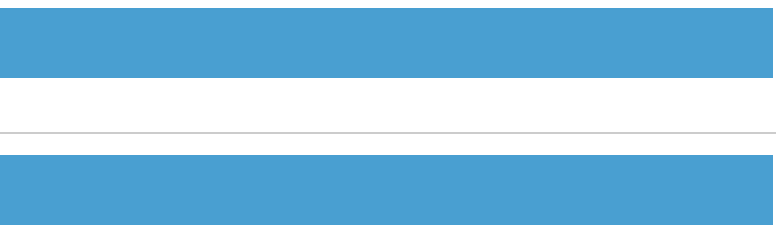

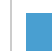

\section{)}

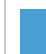
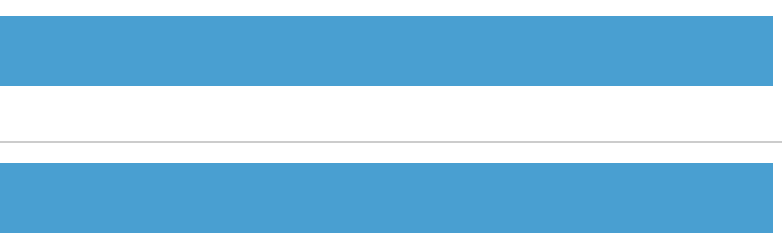
I generally plan for feeding myself. I don't just grab food when I'm hungry. (16)

Mediterranean Diet Score

Q1.35 Do you eat fruit or consume fruit juice every day?

Yes (1)

No (2)

Q1.36 Do you have more than one serving of fruit per day?

Yes (1)

No (2)

Q1.37 Do you regularly consume fresh or cooked vegetables once per day?

Yes (1)

No (2)

Q1.38 Do you regularly consume fresh or cooked vegetables more than once per day?

Yes (1)

No (2)

Q1.39 Do you consume fish 2-3 times per week?

Yes (1)

No (2) 
Q1.40 Do you go to a fast food restaurant more than once per week?

Yes (1)

No (2)

Q1.41 Do you consume beans, peas and/or lentils more than once per week?

Yes (1)

No (2)

Q1.42 Do you consume pasta or rice more than 5 days per week?

Yes (1)

No (2)

Q1.43 Do you eat cereal or grains for breakfast?

Yes (1)

No (2)

Q1.44 Do you consume nuts 2-3 times per week?

Yes (1)

No (2) 
Q1.45 Do you use olive oil in your cooking?

Yes (1)

No (2)

Q1.46 Do you skip breakfast?

Yes (1)

No (2)

Q1.47 Do you consume dairy during breakfast?

Yes (1)

No (2)

Q1.48 Do you consume commercially baked goods or pastries for breakfast?

Yes (1)

No (2)

Q1.49 Do you consume yogurt and/or cheese daily?

Yes (1)

No (2) 
Q1.50 Do you consume sweets and/or candy multiple times per day?
Yes (1)
No (2)

Q1.51 Do you engage in physical activity more than 30 minutes per day or 150 minutes per week?
Yes (1)
No (2)

Q1.52 Do you nap regularly?
Yes (1)
No (2)

Q1.53 Do you get 6-8 hours of sleep per night regularly?
Yes (1)
No (2)

Q1.54 Do you spend less then 1 hour per day watching television?
Yes (1)
No (2) 
Q1.55 Do you spend 2 or more hours with friends on the weekend?

Yes (1)

No (2)

Appendix G: Online Course Modules

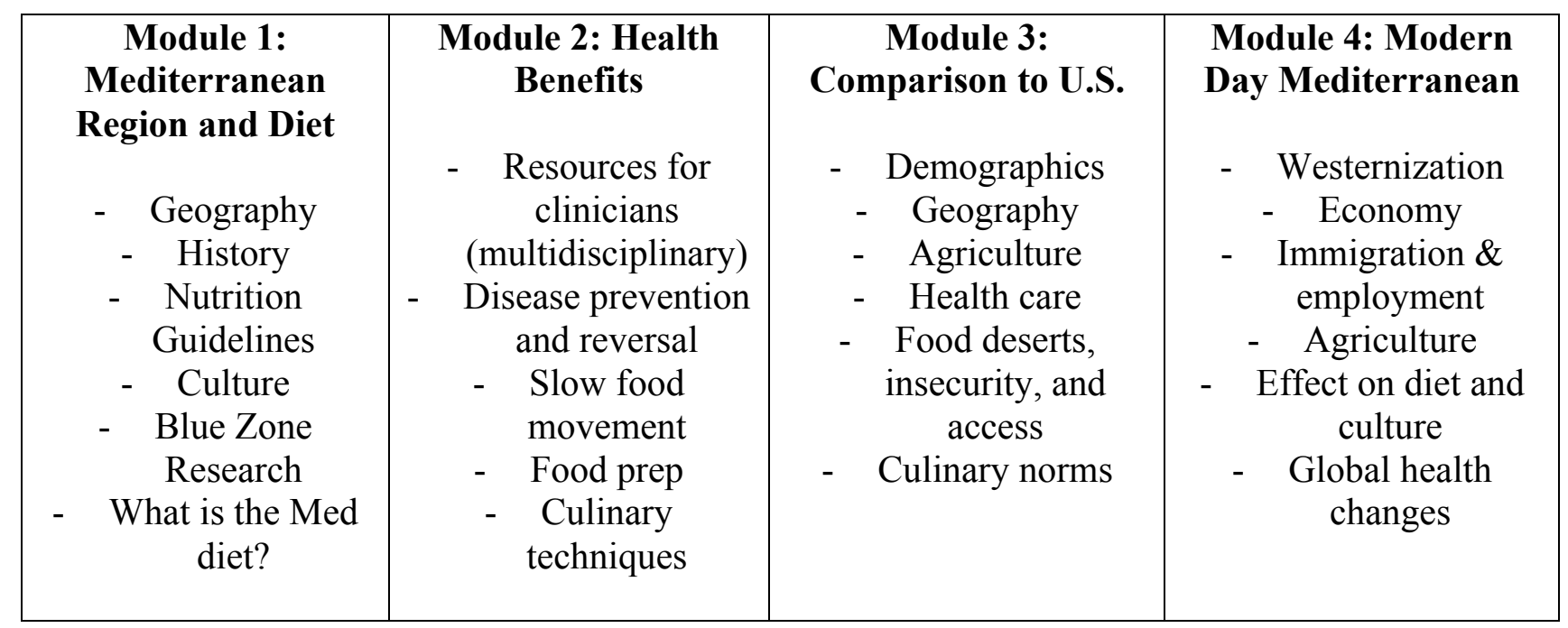

Appendix H: Monthly Involvement Report Survey

1. Research Subject ID:

2. Using the scale below, please indicate to what degree you interacted with Module 1 ( $0=$ did not access the indicated materials, $10=$ watched the entirety of the videos or read indicated materials in full)

$\begin{array}{lllllllllll}0 & 1 & 2 & 3 & 4 & 5 & 6 & 7 & 8 & 9 & 10\end{array}$




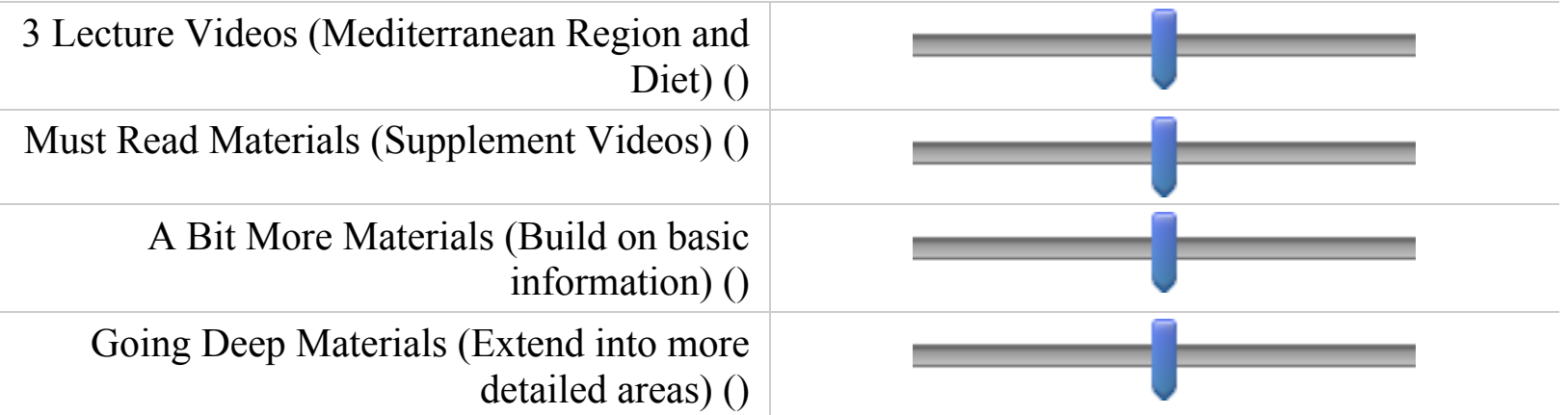

3. Comments about any of your above responses:

4. Please divulge a little about your reflection. Feel free to share your reflection with us, or simply explain how you executed this reflection. (ex: How much time did you spend on reflection of this module's information? Did you begin a journal? Did you discuss with anyone?)

Appendix I: Itinerary

\begin{tabular}{|l|l|}
\hline $\begin{array}{l}\text { Monday } \\
\text { May 21 }\end{array}$ & $\begin{array}{l}\text { Meet at Hotel La Pace in Pisa @ 1:00pm } \\
\text { Travel to Agriturismo \#1 La Valentina }\end{array}$ \\
\hline Muesday 22 & $\begin{array}{l}\text { Breakfast } \\
\text { Buffalo Mozzarella tour and tasting } \\
\text { Lunch at Antica Fattoria del Grottaione Montenero d'Orcia (slow food restaurant) } \\
\text { Frantoio Franci olive press tour and olive oil tasting } \\
\text { Dinner }\end{array}$ \\
\hline $\begin{array}{l}\text { Wednesday } \\
\text { May 23 }\end{array}$ & $\begin{array}{l}\text { Breakfast } \\
\text { LaSelva tour and cook/eat lunch } \\
\text { Roccapesta vineyard tour and wine tasting } \\
\text { Dinner at La Valentina - long and big meal }\end{array}$ \\
\hline $\begin{array}{l}\text { Thursday } \\
\text { May 24 }\end{array}$ & $\begin{array}{l}\text { Breakfast } \\
\text { Parco Maremma } \\
\text { Travel to agriturismo \#2 La Ginestra }\end{array}$ \\
\hline $\begin{array}{l}\text { Friday } \\
\text { May 25 }\end{array}$ & $\begin{array}{l}\text { Breakfast } \\
\text { Corzano \& Paterno cheese and wine tour and tasting } \\
\text { Lunch }\end{array}$ \\
\hline
\end{tabular}




\begin{tabular}{|c|c|}
\hline & $\begin{array}{l}\text { Free time } \\
\text { Dinner }\end{array}$ \\
\hline $\begin{array}{l}\text { Saturday } \\
\text { May } 26\end{array}$ & $\begin{array}{l}\text { Breakfast } \\
\text { Bee keeping } \\
\text { Lunch } \\
\text { Free time } \\
\text { Cook dinner with Jacopo at La Ginestra }\end{array}$ \\
\hline $\begin{array}{l}\text { Sunday } \\
\text { May } 27\end{array}$ & $\begin{array}{l}\text { Breakfast } \\
\text { Free time } \\
\text { Wine tasting } \\
\text { Lunch } \\
\text { Free time } \\
\text { Prepare pizza } \\
\text { Dinner }\end{array}$ \\
\hline $\begin{array}{l}\text { Monday } \\
\text { May } 28\end{array}$ & $\begin{array}{l}\text { Breakfast } \\
\text { Wine museum } \\
\text { Tour ancient grain mill } \\
\text { Cook dinner with Jacopo }\end{array}$ \\
\hline $\begin{array}{l}\text { Tuesday } \\
\text { May } 29\end{array}$ & $\begin{array}{l}\text { Breakfast } \\
\text { Truffle hunting } \\
\text { Truffle lunch } \\
\text { Free time } \\
\text { Dinner }\end{array}$ \\
\hline $\begin{array}{l}\text { Wednesday } \\
\text { May } 30\end{array}$ & $\begin{array}{l}\text { Breakfast } \\
\text { Wine tasting and lunch at Podere Gualandi } \\
\text { Pastificcio Fabbri pasta tour and demo } \\
\text { Piazza Michealangelo (picture stop) } \\
\text { Travel to Hotel Il Granduca } \\
\text { Walking tour of Florence } \\
\text { Free evening }\end{array}$ \\
\hline $\begin{array}{l}\text { Thursday } \\
\text { May } 31\end{array}$ & $\begin{array}{l}\text { Breakfast } \\
\text { Taste of Florence culinary tour } \\
\text { Free afternoon/evening }\end{array}$ \\
\hline $\begin{array}{l}\text { Friday } \\
\text { June } 1\end{array}$ & $\begin{array}{l}\text { Breakfast } \\
\text { Uffizi museum tour } \\
\text { Free afternoon/evening }\end{array}$ \\
\hline $\begin{array}{l}\text { Saturday June } \\
2\end{array}$ & $\begin{array}{l}\text { Breakfast } \\
\text { Cooking lesson at Apicius Culinary Institute }\end{array}$ \\
\hline
\end{tabular}




\begin{tabular}{|l|l|}
\hline & $\begin{array}{l}\text { Lunch } \\
\text { Free afternoon/evening } \\
\text { Conclusion meeting at hotel }\end{array}$ \\
\hline $\begin{array}{l}\text { Sunday } \\
\text { June } 3\end{array}$ & $\begin{array}{l}\text { Breakfast } \\
\text { Departures }\end{array}$ \\
\hline
\end{tabular}

